\title{
The Central Nucleus of the Amygdala Contributes to the Production of Morphine Antinociception in the Rat Tail-Flick Test
}

\author{
Barton H. Manning' and David J. Mayer ${ }^{2}$ \\ Departments of ${ }^{1}$ Anatomy and ${ }^{2}$ Anesthesiology, Medical College of Virginia, Virginia Commonwealth University, \\ Richmond, Virginia 23298
}

\begin{abstract}
Current models of endogenous pain control circuitry emphasize neural substrates within the brainstem and spinal cord. We have recently shown, however, that the central nucleus of the amygdala $(\mathrm{Ce})$ contributes to morphine-induced suppression of formalin-induced nociceptive behaviors. In the four experiments reported here, we investigated the possibility that the $\mathrm{Ce}$ also contributes to morphineinduced suppression of simple, spinally mediated nociceptive reflexes. Bilateral $\mathrm{N}$-methyl-D-aspartate (NMDA)-induced lesions of the rat $\mathrm{Ce}$, but not bilateral lesions centered on either the basolateral or medial amygdaloid nucleus, abolished the antinociception produced by $2.5 \mathrm{mg} / \mathrm{kg}$ morphine sulfate in the noxious heat-evoked tail-flick test. Bilateral Ce lesions also abolished the antinociception produced by 2 or $4 \mathrm{mg} / \mathrm{kg}$ morphine sulfate, but a relatively large dose of morphine sulfate $(10 \mathrm{mg} / \mathrm{kg}, \mathrm{s.c}$.) resulted in partial reinstatement of antinociception. It is unlikely that these effects were due to secondary, seizure-induced damage following NMDA injection (e.g., to areas outside the amygdala) since bilateral inactivation of the Ce with the local anesthetic lidocaine also reliably attenuated morphine antinociception. It is also unlikely that these effects were artifacts of lesion-induced hyperalgesia, since Ce lesions failed to result in reliable thermal hyperalgesia, even at baseline tail-flick latencies of 10-12 sec. These data are the first to provide direct evidence that systemically administered morphine requires the integrity of a forebrain area in order to suppress spinally mediated nociceptive reflexes. It is argued that the present results, together with recent evidence linking the Ce to the production of several forms of conditioned and unconditioned environmentally induced antinociception, warrant incorporation of the $\mathrm{Ce}$ into current models of endogenous pain control circuitry.
\end{abstract}

[Key words: pain, antinociception, morphine, tail flick, amygdala, central nucleus, lesion, NMDA, lidocaine]

Morphine remains one of the most powerful analgesic agents. The CNS substrates underlying morphine's antinociceptive effects have been extensively studied in recent years. Although

\footnotetext{
Received May 4, 1995; revised Aug. 11, 1995; accepted Aug. 17, 1995

This research was supported by PHS Grant NS-24009. We thank Leslie Keniston and Milton Cook for assistance with animal testing, histology, and the preparation of figures. We also thank Drs. J. L. Dupree and J. W. Bigbee for assistance with photography, and Drs. J. Mao, D. D. Price and S. P. Welch for helpful comments and advice.

Correspondence should be addressed to Barton H. Manning, Department of Anatomy, Virginia Commonwealth University, Box 980709, Richmond, VA 23298-0709.

Copyright $(\mathcal{C} 1995$ Society for Neuroscience $0270-6474 / 95 / 158199-15 \$ 05.00 / 0$
}

several different sites of action have been suggested (see Yaksh et al., 1988), the midbrain periaqueductal gray matter (Yaksh et al., 1976; Manning et al., 1994) and spinal cord (Yaksh and Rudy, 1977) are among the more sensitive to direct application of morphine. Furthermore, other neuroanatomical mediators of morphine antinociception (MA) have been established, including circuitry within the rostral ventromedial medulla (sce Ficlds ct al., 1991), and serotonergic and noradrenergic projections (Yaksh, 1979; Jensen and Yaksh, 1986b) descending through the dorsolateral funiculus (DLF; Basbaum et al., 1977; Hayes et al., 1978) to the spinal cord dorsal horn. Based on this and other evidence, a brainstem and spinal cord model of descending antinociceptive circuitry has been proposed (Mayer and Price, 1976; Basbaum and Fields, 1978, 1984; Mayer, 1979) and widely accepted as at least a partial basis for antinociceptive effects of morphine, as well as the antinociceptive effects of some forms of focal brain stimulation and stress (see Basbaum and Fields, 1984; Mayer and Manning, 1995).

Details concerning the microcircuitry and neurotransmitters of endogeneous pain control systems have been extensively investigated (see Fields et al., 1991; Proudfit and Yeomans, 1995). The possible contribution of forebrain areas to the production of MA, however, has met with comparatively little research interest. The few studies concerning this issue have suggested the involvement of such areas as the arcuate nucleus of the hypothalamus (Tseng and Wang, 1992) and area tempestas (d'Amore et al., 1991), but potential interactions of these areas with critical brainstem and spinal cord substrates have not been fully explored.

Several experimenters have recently used the rat paw formalin test to investigate forebrain involvement in the production of MA. The formalin test involves measuring behaviors indicative of prolonged nociception elicited by subcutaneous injection of dilute formalin into a paw (Dubuisson and Dennis, 1977). Several forebrain regions, including the posterior hypothalamic area, evoke antinociception in the formalin test upon direct application of morphine (Manning et al., 1994). Furthermore, the suppression of formalin-induced nociceptive behaviors by systemically administered morphine can be strongly attenuated either by decerebration (Matthies and Franklin, 1992) or by bilateral excitotoxin-induced lesions of the central nucleus of the amygdala (Ce; Manning and Mayer, 1995).

Although the extent of $\mathrm{Ce}$ involvement in the production of MA may be limited to prolonged nociceptive conditions reflected by the formalin test, it is possible that the Ce plays a general role in pain control mechanisms. It is known, for example, that the $\mathrm{Ce}$ entertains reciprocal connections with the PAG (Hopkins 


\section{Ce Sham Lesion}

\section{Ce Lesion}
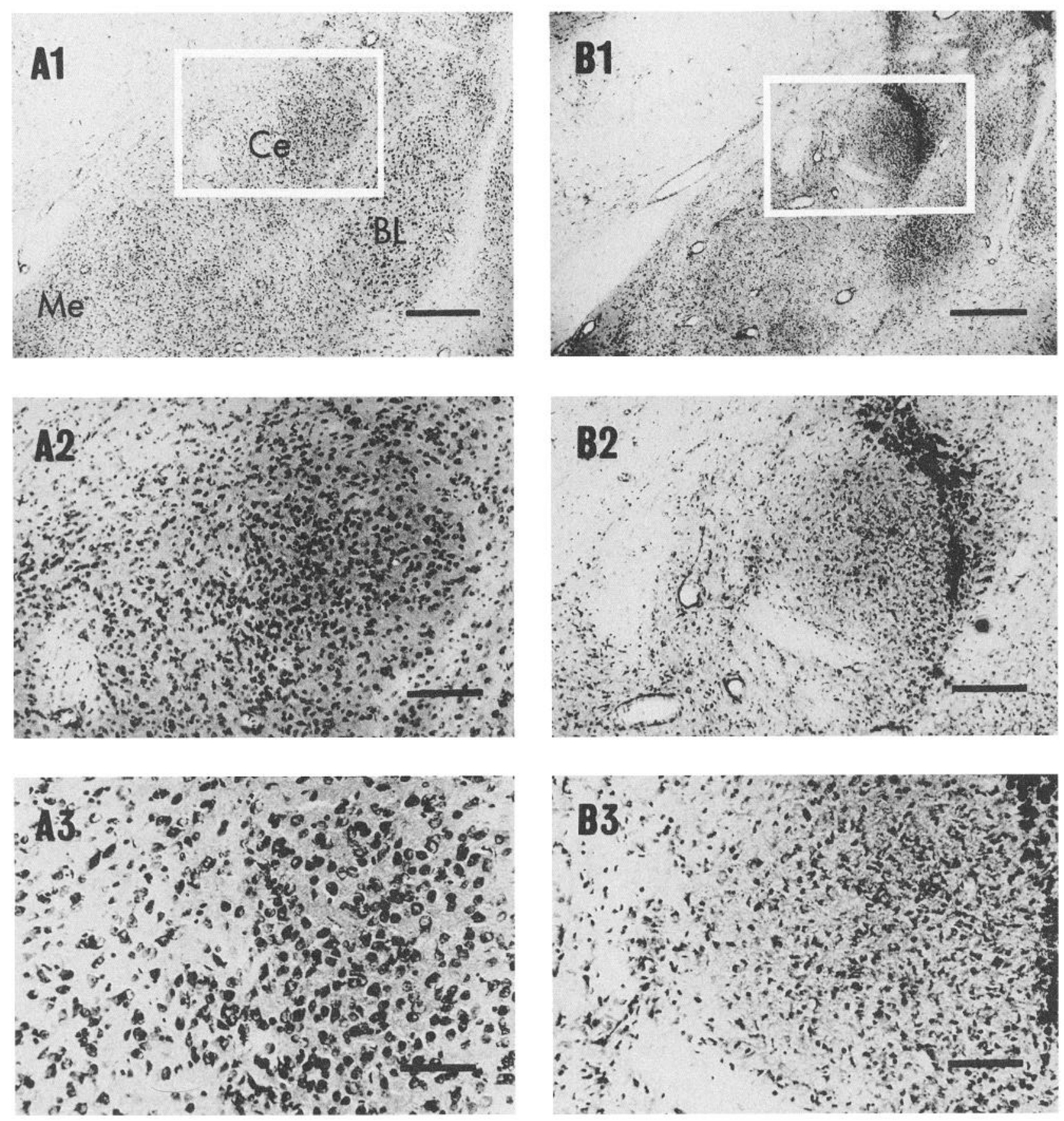

Figure 1. Photomicrographs of coronal sections through the Ce. Al-A3, Progressively higher magnifications showing a portion of Ce infused with $0.1 \mathrm{M}$ PBS corresponding to a rat in the Ce sham-lesion group of Experiment 1 . Note the healthy neuronal cell profiles. B1-B3, Progressively higher magnifications showing a portion of $\mathrm{Ce}$ infused with NMDA $(0.25 \mathrm{M}, \mathrm{pH} 7.4)$ corresponding to a rat in the Ce lesion group of Experiment 1. Note the marked decrease in neuronal cell profiles and proliferation of smaller glial cells. Cresyl violet stain. Scale bars: $A l$ and $B 1,400 \mu m$; $A 2$ and $B 2,200 \mu \mathrm{m} ; A 3$ and $B 3,100 \mu \mathrm{m}$.

and Holstege, 1978; Rizvi et al., 1991), an area well known for its ability to evoke suppression of spinally mediated nociceptive reflexes (Mayer et al., 1971; Yaksh et al., 1988). Furthermore, bilateral lesions of the amygdala (including the $\mathrm{Ce}$ ) attenuate several forms of environmentally induced antinociception as measured on assays involving both brief (Helmstetter and Bellgowan, 1993; Fox and Sorenson, 1994) and prolonged (Helmstetter, 1992) nociception.

In the following series of experiments, we investigated the possibility that the Ce contributes to morphine-induced suppres- 


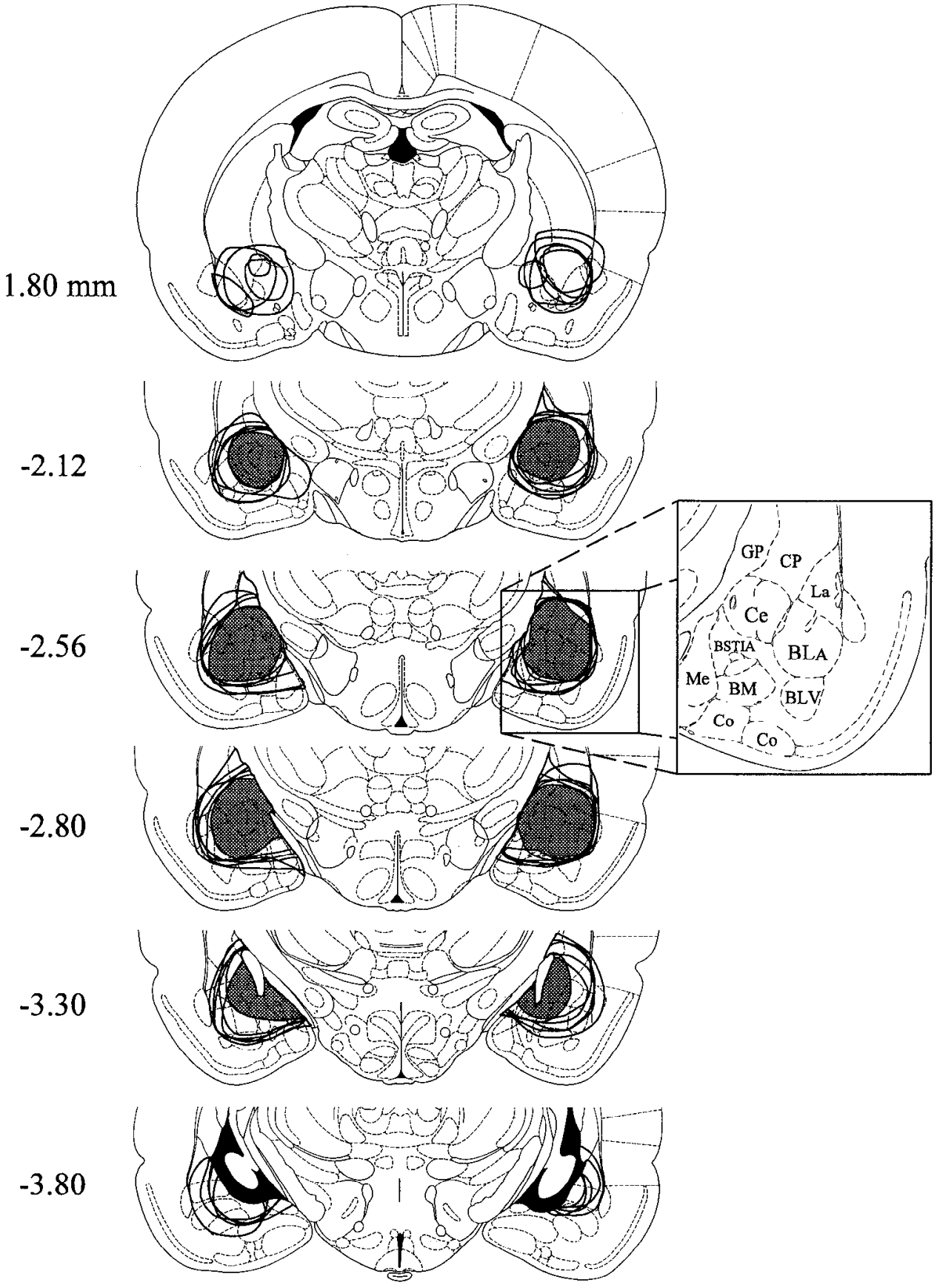

Figure 2. Histological results of Experiment 1 (bilateral Ce lesions). Representations of six coronal sections through the rat forebrain are shown in sequence from anterior to posterior. Millimeters postcrior to bregma are given to the left. The closed curves illustrate the borders of Ce lesions ( $n=$ 6 ), as determined by the extent of neuronal cell loss and gliosis. Lesion area common to all six rats is shown as dark shading in each hemisphere. Note that over $80 \%$ of the $\mathrm{Ce}$ was bilaterally damaged in all six rats. Adapted from Paxinos and Watson (1986). Amygdaloid areas: $C e$, central nucleus; $B L A$, basolateral nucleus, anterior; $B L V$, basolateral nucleus, ventral; BSTIA, bed nucleus of the stria terminalis, intraamygdaloid division; $M e$, medial nucleus; $B M$, basomedial nucleus; $C o$, cortical amygdaloid nuclei. Extraamygdaloid areas: $G P$, globus pallidus; $C P$, caudate-putamen.

sion of the noxious heat-evoked, spinally mediated tail-flick (TF) reflex. We bilaterally inactivated neurons within the rat $\mathrm{Ce}$ in two ways: (1) through focal infusion of a small volume of the excitotoxin $N$-methyl-D-aspartate (NMDA), which destroys neu ronal somata within a brain region but not fibers of passage (Hastings et al., 1985; Winn et al., 1990, 1991), and (2) through focal infusion of a small volume of the local anesthetic lidocaine, which produces temporary, nonspecific, neuronal blockade (Sandkühler et al., 1987; Martin, 1991). The antinociceptive effects of several doses of systemically administered morphine were then tested in awake, Ce-inactivated rats.

\section{Experiment 1}

The purpose of this experiment was to test the ability of a single dose of morphine sulfate $(2.5 \mathrm{mg} / \mathrm{kg})$ to suppress the TF reflex in rats with bilateral, excitotoxin-induced lesions of the Ce. In addition to a $\mathrm{Ce}$ sham-lesion control group, treatment groups of rats with bilateral lesions or bilateral sham lesions centered on the basolateral nucleus of the amygdala (BL) or medial nucleus of the amygdala (Me) were also prepared and tested.

\section{Materials and Methods}

Subjects. Experimentally naive, male Sprague-Dawley rats (Hilltop, Scottdale, PA) weighing $300-325 \mathrm{gm}$ at the time of surgery were used. Animals were housed individually in cages on a 12:12 light/dark schedulc (lights on at 7:00 A.M.) with food and water available ad libitum. All experimental procedures were approved by the Institutional Animal Care and Use Committee of Virginia Commonwealth University.

Experimental design. Three sets of lesion animals (Ce-lesion, BLlesion, and Me-lesion) and three sets of sham-lesion animals (Ce-, BL-, and Me-sham lesion) were surgically prepared for this experiment. An- 


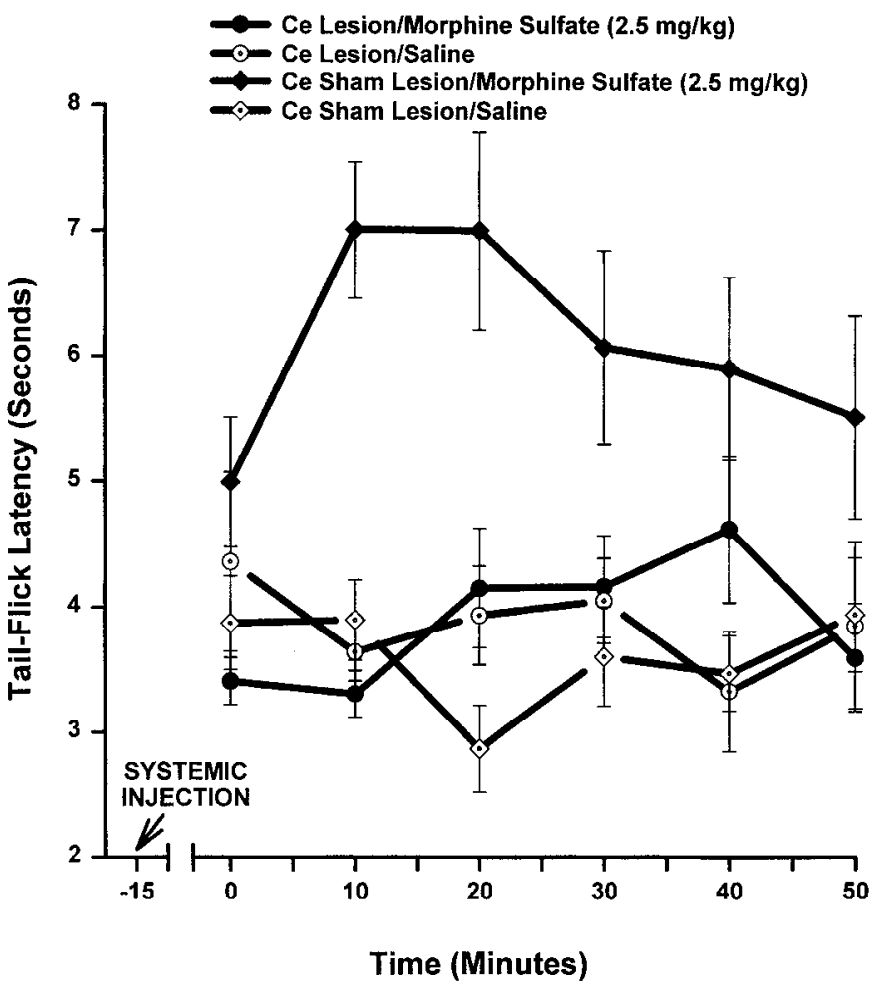

Figure 3. Mean TFLs of Ce-treated rats ( $n=6$ /group) in Experiment 1. Error bars indicate SEM. Baseline (i.e., systemic saline) TF latencies of Ce lesion rats were not reliably different from those of $\mathrm{Ce}$ shamlesion rats (protected $t$ test, $P>0.05$ ). In Ce sham-lesion rats, administration of morphine sulfate $(2.5 \mathrm{mg} / \mathrm{kg}, \mathrm{s.c}$.) resulted in reliable elevation of TF latencies as compared with saline (protected $t$ test, $P<$ 0.01 ), indicating the production of reliable antinociception. In Ce lesion rats, however, the same dose of morphine was ineffective in producing reliable antinociception (protected $t$ test, $P<0.01$ ).

imals were allowed to recover for at least $7 \mathrm{~d}$ before nociceptive testing began. If, however, an animal had not regained $100 \%$ of its preoperative body weight by postsurgical day 10 , it was not included in the study. Each animal received two nociceptive test sessions, with each test session separated by $7 \mathrm{~d}$. Before each session, the animal received a subcutaneous injection of either morphine sulfate $(2.5 \mathrm{mg} / \mathrm{kg})$ or saline vehicle. Beginning $15 \mathrm{~min}$ after the injection, TF latencies (TFLs; procedure described below) were obtained at $10 \mathrm{~min}$ intervals for $50 \mathrm{~min}$. The order of systemic drug administration was counterbalanced within each group.

The dose of $2.5 \mathrm{mg} / \mathrm{kg}$ morphine sulfate was chosen for this initial experiment because in normal rats it produces reliable, yet submaximal, suppression of the TF reflex when baseline TFLs of 3-4 sec are used. It was hoped that by using this dose, quantitative differences between the Ce lesion group and the various control groups would be readily detectable.

Surgery. Rats were anesthetized with sodium pentobarbital $(48 \mathrm{mg} /$ $\mathrm{kg}$, i.p.). Using standard stereotaxic equipment, stainless steel injection cannulas (30 gauge) were lowered bilaterally into either the $\mathrm{Ce}, \mathrm{BL}$, or $\mathrm{Me}$, based on coordinates provided by the atlas of Paxinos and Watson (1986; Ce coordinates: AP $-2.5 \mathrm{~mm}$ posterior to bregma, lateral \pm 4.4 $\mathrm{mm}$, ventral $8.3 \mathrm{~mm}$; BL, coordinates: AP $-2.5 \mathrm{~mm}, \mathrm{I} \pm 5.2, \mathrm{~V}-8.3$; Me coordinates: AP $-2.5 \mathrm{~mm}, \mathrm{~L}-3.2, \mathrm{~V}-9.4)$. The cannulas were connected, via polyethylene tubing, to syringes mounted on an infusion pump (Harvard Apparatus, South Natick, $M \Lambda$ ). $\Lambda$ fter 5 min, either $N$-methyl-D-aspartate (NMDA; $0.25 \mathrm{M}$ in sterile, isotonic $0.1 \mathrm{M} \mathrm{PBS}$, $\mathrm{pH} 7.4$ ) or vehicle alone was slowly infused into the target site over 5 min such that the final volume of injection was 150 nl. The cannulas were left in place an additional $5 \mathrm{~min}$ to allow sufficient time for absorption. The cannulas were then removed, and the scalp wound closed with wound clips. Each rat received an injection of diazepam (1 mg, i.p.) and rats treated with NMDA were monitored for early signs of seizure activity until they awoke from anesthesia. If an NMDA-treated rat showed any signs of seizure activity, an additional injection of diazepam (1 mg, i.p.) was administered.

Nociceptive testing. Ambient temperature of the test room was maintained at $24 \pm 0.5^{\circ} \mathrm{C}$ at all times. Each rat was positioned in a well ventilated, tube-shaped plastic restrainer (internal diameter, $6.5 \mathrm{~cm}$; internal length, $25 \mathrm{~cm}$ ), to which the rat was habituated for $1 \mathrm{hr}$ on each of $3 \mathrm{~d}$ immediately prior to testing. The TFL was defined as the time from the onset of radiant heat to withdrawal of the tail (D'Amour and Smith, 1941). The radiant heat source came from a projection bulb underneath a $3 \mathrm{~mm}$ thick glass plate. The bulb was aimed at the caudal end (4-10 cm from the tail tip) of the rat's tail. The intensity of heat emitted by the bulb was adjusted using a rheostat to result in baseline (i.e., systemic saline) TFLs of $3.0-4.0 \mathrm{sec}$. An automatic cutoff time of $8 \mathrm{sec}$ was preset to minimize possible tissue damage caused by overstimulation in the absence of a withdrawal response. For each time point tested, three TF trials were made with (1) a 1 min intertrial interval (Depaulis et al., 1987) and (2) changes in the position of the tail receiving heat stimulation on each trial. The mean TFL from the three trials was used as the nociceptive score for that time point. Testing was performed blind as to which treatment group the subject belonged.

Histology. After completion of the second TF test session, rats were overdosed with sodium pentobarbital $(100 \mathrm{mg} / \mathrm{kg})$ and perfused through the heart with buffered $0.9 \%$ saline followed by $10 \%$ formalin. The brains were removed and stored overnight in a buffered $10 \%$ formalin/ $10 \%$ sucrose solution. The following morning the brains were quickly frozen and sliced at $-25^{\circ} \mathrm{C}$. Coronal sections ( $20 \mu$ m thick) were laken starting at the crossing of the anterior commissure and ending at the caudal limit of the PAG, and stained with cresyl violet. Brains infused with NMDA were inspected with a light microscope for gliosis and neuronal cell loss as compared with brains infused with PBS (Hastings et al., 1985; Winn et al., 1990, 1991). Since the Ce projects to the ventrolateral PAG (Hopkins and Holstege, 1978; Beitz, 1982; Rizvi et al., 1991), and the ventrolateral PAG is an important site of morphine action in the TF test (e.g. Jensen and Yaksh, 1986a), the brains of lesion rats were also inspected for signs of transsynaptic neuronal cell loss in the PAG as compared with sham-lesion rats. Rat subjects were included for statistical analysis if the nucleus targeted for destruction was damaged by at least $80 \%$ in each hemisphere. In the case of BL and $\mathrm{Me}$ lesion rats, a damage level of $20 \%$ or less bilaterally to the $\mathrm{Ce}$ was permitted. Lesion mapping was performed blind to the behavioral results.

Statistical analyses. TFLs collected from Ce-treated rats (lesion and sham lesion), BL-treated rats (lesion and sham lesion), and Me-treated rats (lesion and sham lesion) were analyzed in separate three-factor ANOVAs (lesion $\times$ systemic drug treatment $\times$ time), with systemic drug treatment and time analyzed as repeated measures. Multiple pairwise comparisons were made using protected $t$ tests.

\section{Results}

Recovery from surgery

In the present experiment, as well as in Experiments 3 and 4 (see below), most rats treated with intra-amygdaloid NMDA appeared to recover well from surgery, with an average of one in 20 prepared rats failing to regain $100 \%$ preoperative body weight by postsurgical day 10 . All rats receiving intra-amygdaloid infusion of PBS regained $100 \%$ body weight before postsurgical day 7 .

\section{Histology}

Bilateral intra-Ce infusion of excitotoxic levels of NMDA produced lesions with a pattern of neuronal cell loss and proliferation of small glial cells (Fig. 1). In all cases, the lesion had clearly definable borders, with substantial loss of neuronal cell profiles and proliferation of glial elements on one side of the border, and healthy neuronal cell profiles on the other side of the border. Infusion of NMDA into the $\mathrm{BL}$ or $\mathrm{Me}$ was also extremely effective in producing neuronal cell loss, with proliferation of glial cells being even more pronounced than that observed after NMDA infusion into the Ce. Lesions corresponding to rats included in the Ce lesion group $(n=6)$, BL lesion group 


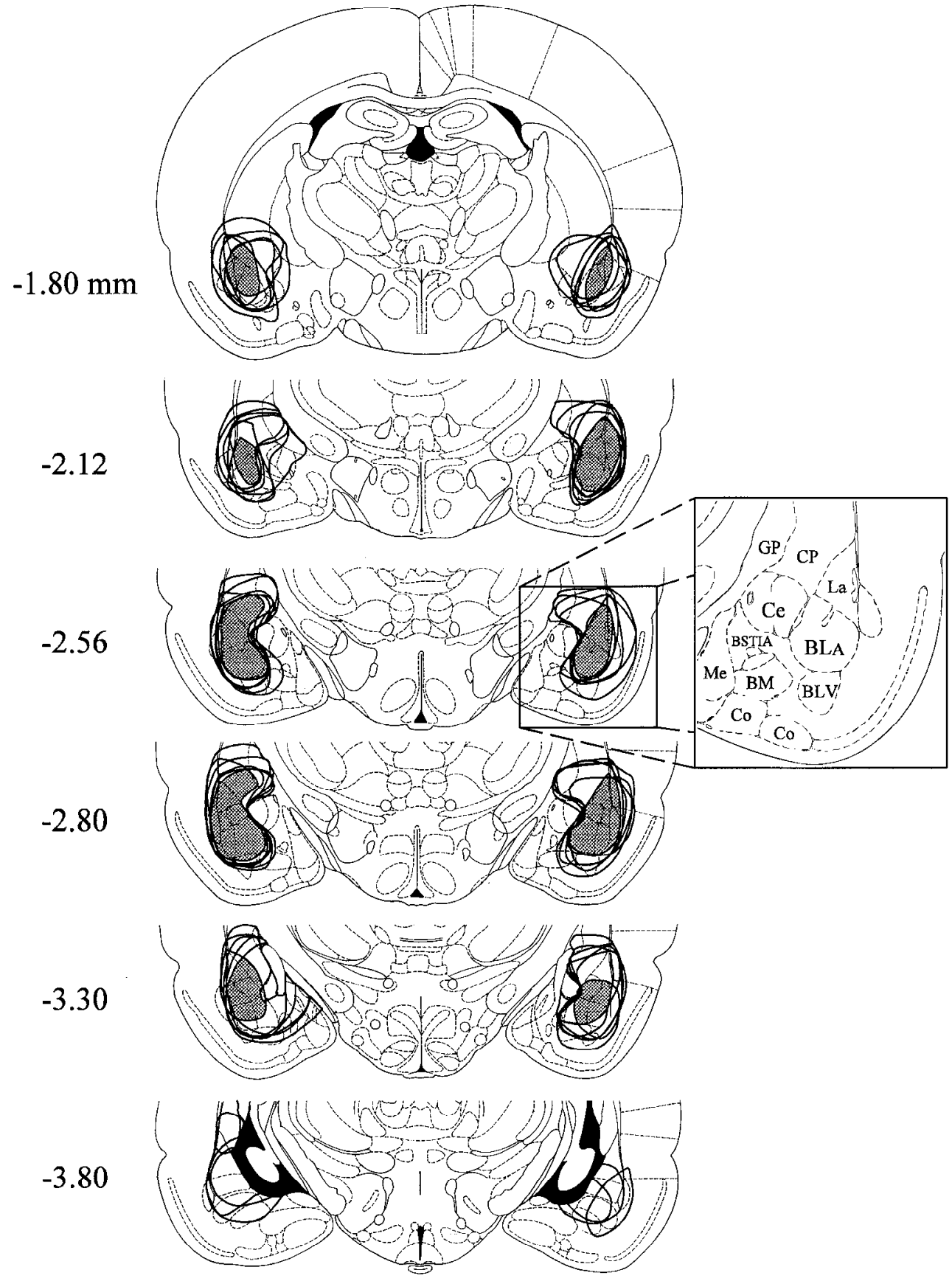

Figure 4. Histological results of Experiment 1 (bilateral BL lesions). Representations of six coronal sections through the rat forebrain are shown in sequence from anterior to posterior. Millimeters posterior to bregma are given to the left. The closed curves illustrate the borders of BL lesions $(n=6)$, as determined by the extent of neuronal cell loss and gliosis. Lesion area common to all six rats is shown as light shading in each hemisphere. Adapted from Paxinos and Watson (1986). Amygdaloid areas: $C e$, central nucleus; $B L A$, basolateral nucleus, anterior; $B L V$, basolateral nucleus, ventral; $B S T I A$, bed nucleus of the stria terminalis, intraamygdaloid division; $M e$, medial nucleus; $B M$, basomedial nucleus; $C o$, cortical amygdaloid nuclei. Extra-amygdaloid areas: $G P$, globus pallidus; $C P$, caudate-putamen. $(n=6)$, and Me lesion group $(n=8)$ are outlined in Figures 2,4 , and 6 , respectively. The shading in each of these figures indicates damaged tissue common to all rats in the group.

Ce-treated rats. Of the 14 rats initially prepared for the Celesion group, six met the strict inclusion criterion of $80 \%$ bilateral Ce damage. Cases were rejected on the basis of insufficient bilateral $\mathrm{Ce}$ damage or sufficient damage to the $\mathrm{Ce}$ in one hemisphere only. In four of the six Ce lesion cases, neuronal cell loss was evident in all portions of the $\mathrm{Ce}$ (including the medial and lateral subdivisions) in one hemisphere, and in $85-90 \%$ of the $\mathrm{Ce}$ in the other hemisphere (Fig. 2). In the other two cases, neuronal cell loss was evident in $85-90 \%$ of the Ce bilaterally. In all six cases, neuronal damage extended dorsally into portions of overlying globus pallidus and caudate-putamen. Furthermore, in all six cases, there was substantial bilateral damage to the $\mathrm{BL}$ and portions of the lateral nucleus in addition to varying amounts of bilateral damage to the intra-amygdaloid division of the bed nucleus of the stria terminalis. The posterodorsal subdivision of the Me was damaged bilaterally by approximately $50 \%$ in three cases, with the other three cases showing substantial Me damage in one hemisphere but not the other.

$B L$-treated rats. Six out of 14 prepared rats met the inclusion criterion for the BL lesion group. In all six BL lesion cases, there was substantial bilateral neuronal cell loss in at least $80 \%$ of the BL, with the ventral subdivision of the BL being most frequently spared by the NMDA treatment (Fig. 4). In all cases, a large percentage of the lateral nucleus and smaller percentages of adjacent piriform cortex and overlying caudate-putamen and globus pallidus were damaged bilaterally. Furthermore, damage extended bilaterally into the lateral portion of the $\mathrm{Ce}(\mathrm{CeL})$ in 


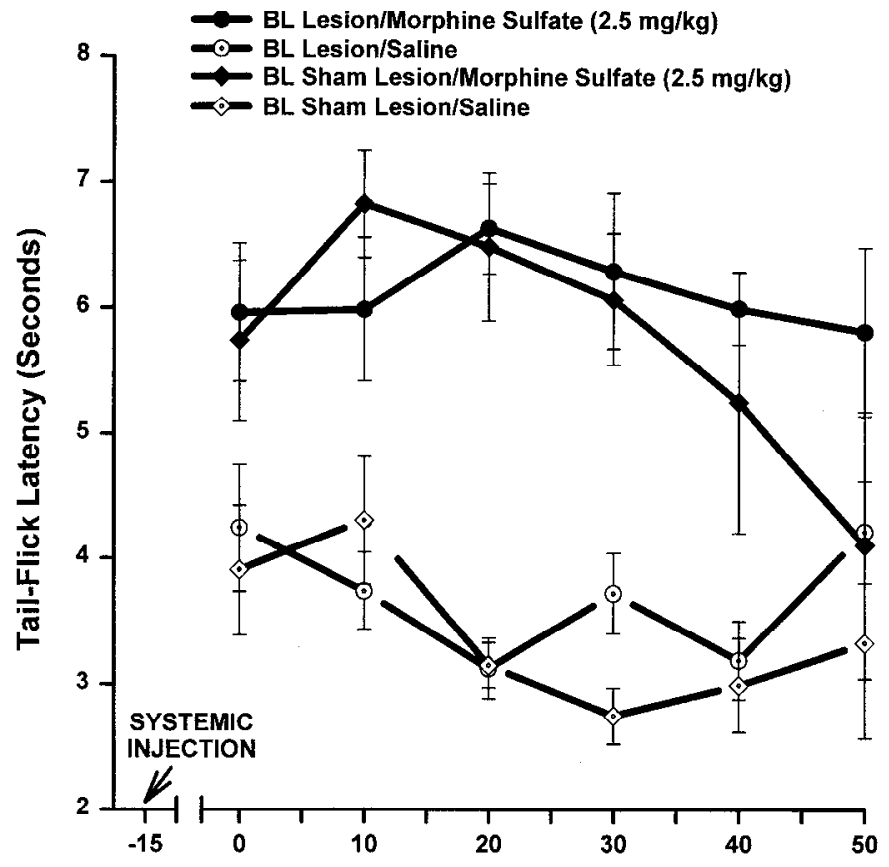

Time (Minutes)

Figure 5. Mean TF latencies of BL-treated rats ( $n=6 /$ group $)$ in Experiment 1. Error bars indicate SEM. Baseline (i.e., systemic saline) TF latencies of BL lesion rats were not reliably different from those of $\mathrm{BL}$ sham-lesion rats (protected $t$ test, $P>0.05$ ). Unlike the effect observed in rats with bilateral Ce lesions (Fig. 3), the ability of morphine sulfate $(2.5 \mathrm{mg} / \mathrm{kg}$, s.c.) to produce antinociception was not compromised by bilateral lesions of the BL (protected $l$ test, $P>0.05$ ).

all cases, although in five cases the damage was very slight. In the other case the Ce was damaged by approximately $15 \%$ in one hemisphere, while the $\mathrm{Ce}$ in the other hemisphere remained intact except for slight damage around the border of the CeL.

Me-treated rats. Fight out of 14 prepared rats met the inclusion criterion for the Me lesion group. In all eight Me lesion cases, there was substantial bilateral neuronal cell loss in at least $80 \%$ of the Me with dorsal portions of the Me being the most frequently spared (Fig. 6). In all cases, there was substantial damage to portions of the cortical amygdaloid nuclei and basomedial amygdaloid nucleus. Furthermore, in one case there was bilateral neuronal cell loss in the medial subdivision of the $\mathrm{Ce}(\mathrm{CeM})$. This damage, however, did not exceed $20 \%$ of the total area of that nucleus. In another five cases, there was slight damage around the medial border of the CeM in one hemisphere with the $\mathrm{Ce}$ in the other hemisphere left completely intact.

The histological results depicted in Figures 2, 4, and 6 are combined in Figure 8 to show lesion area common to all rats in the $\mathrm{Ce}$ lesion group (dark shading), and how this area relates to lesion area common to rats in the Me and BL groups (light shading). Note that while the bilateral Ce lesions also consistently resulted in substantial neuronal cell loss in the $\mathrm{BL}, \mathrm{Me}$, and lateral amygdaloid nucleus, this damage was largely controlled for in the $\mathrm{BL}$ and Me lesion groups.

No lesion rats showed signs of neuronal cell loss or gliosis when examined along the rostral-caudal extent of the PAG.

\section{Nociceptive scores}

Ce-treated rats. TFLs of Ce-treated rats (lesion and sham lesion) are shown in Figure 3. An ANOVA revealed reliable interactions between lesion and systemic drug treatment $[F(1,10)=12.30$, $P<0.01]$, and systemic drug treatment and time $[F(5,50)=$ $3.68, P<0.01]$. Further analysis of the lesion $\times$ systemic drug treatment interaction showed that morphine sulfate $(2.5 \mathrm{mg} / \mathrm{kg})$ produced reliably higher TFLs than saline in Ce sham-lesion rats (Fig. 3; protected $t$ test, $P<0.01$ ), indicating reliable antinociception had occurred. Morphine, however, failed to produce reliably higher TFLs than saline in Ce lesion rats (Fig. 3; protected $t$ test, $P>0.05$ ). Finally, the TFLs of Ce lesion rats treated with saline were not reliably different from THLs displayed by Ce sham-lesion rats treated with saline (Fig. 3; protected $t$ test, $P$ $>0.05)$.

BL-treated rats. TFLs of BL-treated rats (lesion and sham lesion) are shown in Figure 5. An ANOVA revealed a reliable interaction between systemic drug treatment and time $[F(5,50)$ $=6.01, P<0.001]$. There was, however, no reliable main effect of lesion $[F(1,10)=0.895, P>0.05]$, indicating that TFLs of $\mathrm{BL}$ lesion and $\mathrm{BL}$ sham-lesion rats were not reliably different overall. Further analysis of the systemic drug treatment $\times$ time interaction showed that morphine produced reliably higher TFLs than saline (indicating reliable antinociception) in BL-treated rats at all time points (Fig. 5; protected $t$ tests, $P<0.01$ ) except the last, at 65 min after morphine injection (Fig. 5; protected $t$ test, $P>0.05$ ).

Me-treated rats. TFLs of Me-treated rats (lesion and sham lesion) are shown in Figure 7. An ANOVA revealed a reliable three-way interaction between lesion, systemic drug treatment, and time $[F(5,70)-2.76, P<0.02]$. Morphine sulfate $(2.5 \mathrm{mg} /$ $\mathrm{kg}$ ) produced reliably higher TFLs than saline in Me sham-lesion rats at all time points tested except the first (Fig. 7; protected $t$ tests, $P<0.01$ at all time points), indicating the production of reliable antinociception. Morphine also produced reliably higher TFLs than saline in Me lesion rats at all time points tested (Fig. 7; protected $t$ tests, $P<0.05$ ), indicating reliable antinociception was also produced in Me lesion rats. TFLs did not differ at any time point between $\mathrm{Me}$ sham-lesion rats treated with morphine and Me lesion rats treated with morphine (Fig. 7; protected $t$ tests, $P>0.05$ at all time points). Finally, no reliable differences in baseline (i.e., systemic saline) TFLs were detected between Me lesion and Me sham-lesion rats (Fig. 7; protected $t$ tests, $P$ $>0.05$ at all time points), except at 15 min after saline injection, when Me sham-lesion rats showed reliably higher TFLs than Me lesion rats (Fig. 7; protected $t$ test, $P<0.01$ ).

\section{Experiment 2}

The results of Experiment 1 suggest that bilateral NMDA-induced lesions of the $\mathrm{Ce}$, but not bilateral lesions of the $\mathrm{BL}$ or $\mathrm{Me}$, attenuate the antinociceptive effects of systemically administered morphine in the TF test. It should be pointed out, however, that intracerebral infusion of neurotoxic levels of excitatory amino acids such as NMDA, ibotenate, or kainate has becn reported to result in seizure activity (e.g., Winn et al., 1991). Furthermore, in the case of kainate at least, such seizure activity may result in secondary neuronal damage in brain areas remote from the site of injection (e.g., Ben-Ari et al., 1979; Köhler and Schwarcz, 1983). In our experience, intra-amygdaloid microinjection of buffered NMDA does not produce strong seizure activity, and early signs of such activity can be easily controlled by diazepam (see Experiment 1, Materials and Methods). Furthermore, the histological results of Experiment 1 revealed no obvious signs of neuronal damage to PAG neurons in Ce lesion rats. Nevertheless, the possibility of seizure-induced toxic effects 


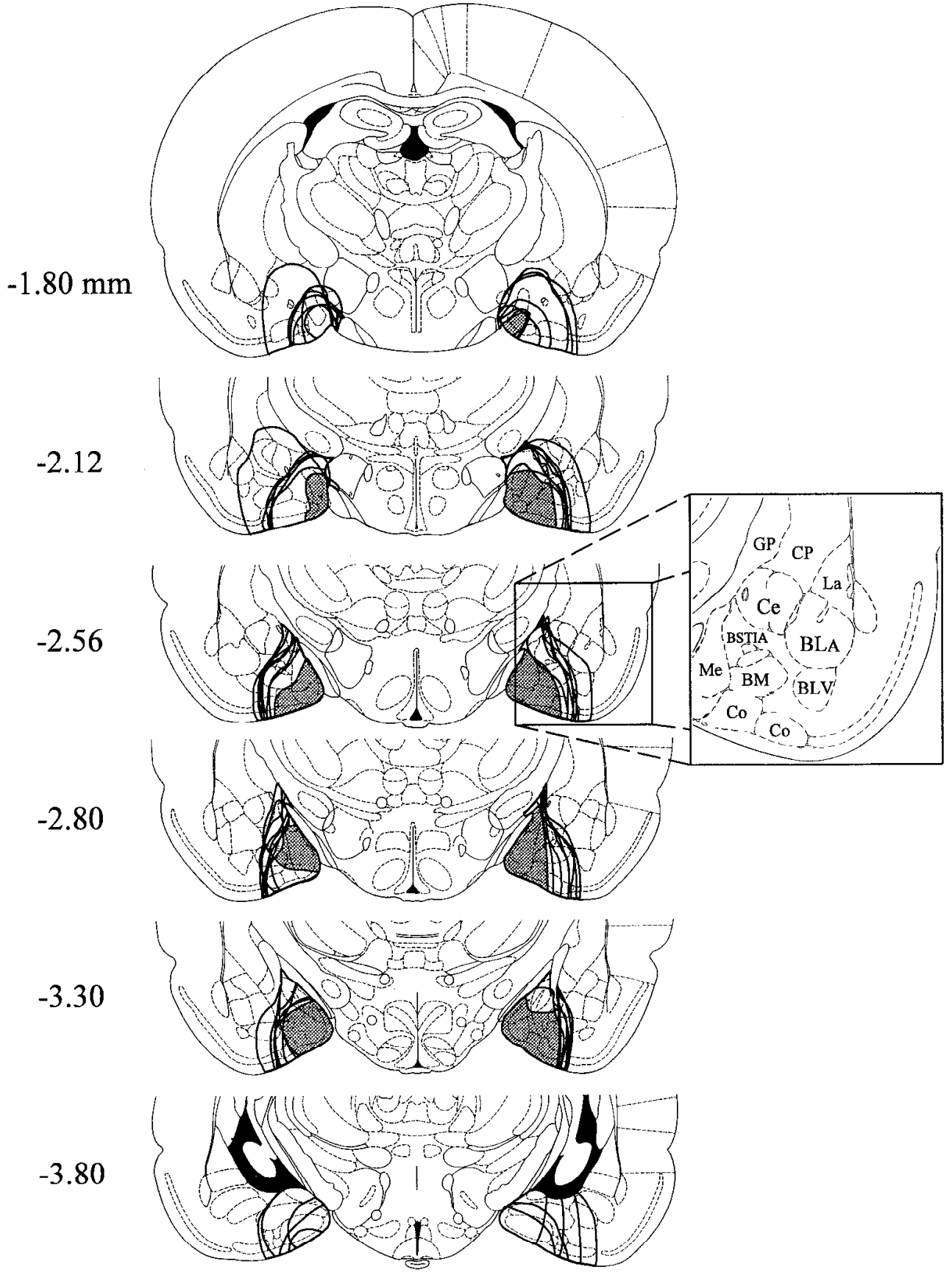

Figure 6. Histological results of Experiment 1 (bilateral Me lesions). Representations of six coronal sections through the rat forebrain are shown in sequence from anterior to posterior. Millimeters posterior to bregma are given to the left. The closed curves illustrate the borders of Me lesions $(n=$ 8 ), as determined by the extent of neuronal cell loss and gliosis. Lesion area common to all eight rats is shown as light shading in each hemisphere. Adapled from Paxinos and Watson (1986). Amygdaloid areas: $C e$, central nucleus; $B L A$, basolateral nucleus, anterior; $B L V$, basolateral nucleus, ventral; BSTIA, bed nucleus of the stria terminalis, intra-amygdaloid division; $M e$, medial nucleus; $B M$, basomedial nucleus; $C o$, cortical amygdaloid nuclei. Extra-amygdaloid areas: $G P$, globus pallidus; $C P$, caudate-putamen. to areas outside the amygdala cannot be completely discounted. Accordingly, we sought to determine whether bilateral intra-Ce microinjections of the local anesthetic lidocaine would also result in attenuation of MA in the TF test. Lidocaine produces temporary, nonspecific, neuronal blockade within an injection area, including blockade of fibers of passage (e.g., Sandkühler et al., 1987; Martin, 1991). It would not, however, be expected to produce neuronal blockade in brain areas remote from the site of injection.

\section{Materials and Methods}

Surgery. Rats were anesthetized as described in Experiment 1. Stainless steel guide cannulas (23 gauge) were stereotaxically placed bilaterally $2 \mathrm{~mm}$ above the $\mathrm{Ce}$ according to the atlas of Paxinos and Watson (1986; coordinates: AP $-2.5 \mathrm{~mm}$ posterior to bregma, lateral $\pm 4.4 \mathrm{~mm}$, ventral $6.3 \mathrm{~mm}$ ). A stainless steel stylet (00 gauge), extending just past the tip of the guide cannula, kept it free of debris during the surgical recovery period. The recovery period lasted $7 \mathrm{~d}$.

Experimental design. After surgery, animals were randomly chosen for inclusion in either an intra-Ce lidocaine treatment group or an intra$\mathrm{Ce}$ saline treatment group. Each of these groups in turn received two TF sessions spaced $7 \mathrm{~d}$ apart: (1) a session beginning with a subcutaneous injection of morphine sulfate $(2.5 \mathrm{mg} / \mathrm{kg})$, and (2) a session beginning with a subcutaneous injection of saline vehicle. Each test session began with the subcutaneous injection, whereupon the rat immediately started the microinjection procedure. Each stylet was removed from its respective guide cannula, and replaced with a 30 gauge inner cannula extending $2 \mathrm{~mm}$ beyond the tip of the guide cannula. Beginning at $5 \mathrm{~min}$ after subcutaneous injection, the intra-Ce injectate (either $2.0 \%$ lidocaine $\mathrm{HCl}$ in sterile, isotonic $0.1 \mathrm{M}$ PBS, pH 7.4, or $0.1 \mathrm{M}$ PBS alone) was slowly infused over $5 \mathrm{~min}$ such that the final volume of injection was $250 \mathrm{nl}$ bilaterally. The inner cannulas were left in placc for an additional two min to allow sufficient time for absorption of injectate into local tissue. The rat was then immediately placed in the 


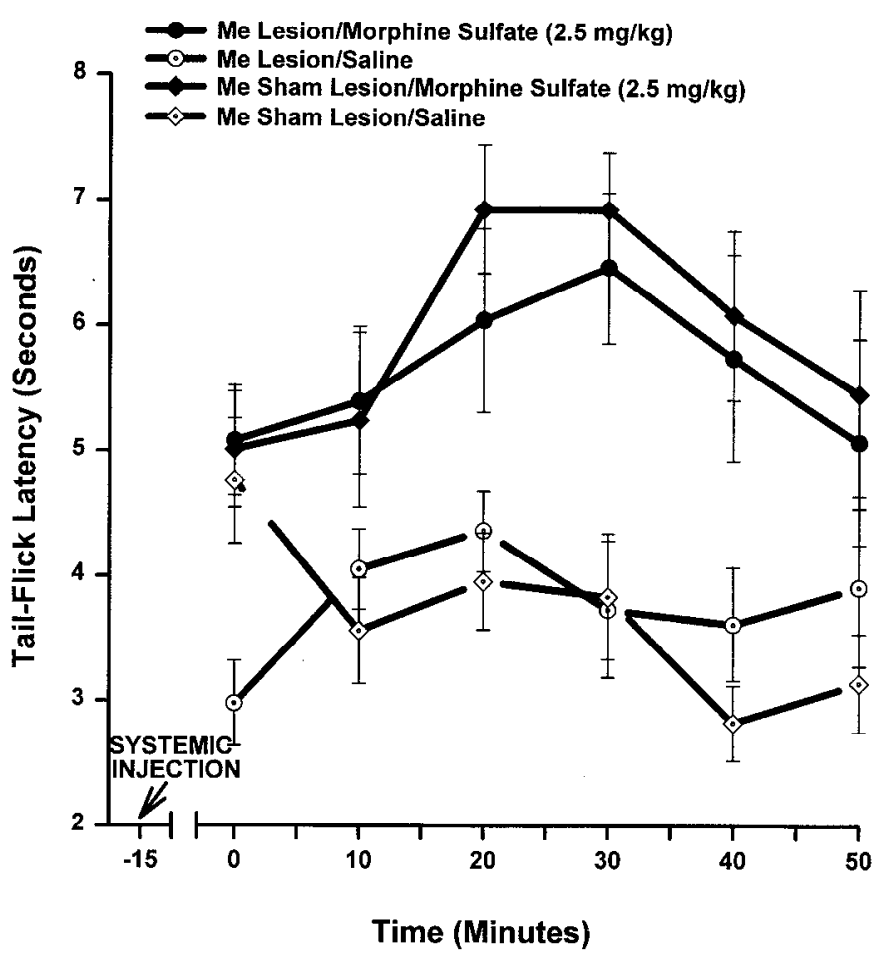

Figure 7. Mean TF latencies of Me-lesion $(n=8)$ and Me shamlesion ( $n=7)$ rats in Experiment 1. Error bars indicate SEM. Baseline (i.e., systemic saline) TF latencies of Me lesion rats were not different from those of Me sham-lesion rats (protected $t$ test, $P>0.05$ ). Unlike the effect observed in rats with bilateral Ce lesions (Fig. 3), the ability of morphine sulfate $(2.5 \mathrm{mg} / \mathrm{kg}$, s.c.) to produce antinociception was not compromised by bilateral lesions of the Me (protected $t$ test, $P>$ $0.05)$.

plastic restraint tube (see Experiment 1). TF testing began 15 min after subcutaneous drug injection. TFIs were obtained at $10 \mathrm{~min}$ intervals for the next $50 \mathrm{~min}$ (see Experiment 1, Materials and Methods, Nociceptive testing). The order of systemic drug administration was counterbalanced within each group.

After completion of the second TF session, rats were perfused through the heart and their brains removed and stored in sucrose/formalin as described in Experiment 1. The brains were quickly frozen and sliced at $-25^{\circ} \mathrm{C}$. Coronal sections ( $20 \mu \mathrm{m}$ thick) were taken through the amygdala and stained with cresyl violet. The tips of the inner cannulas were determined bilaterally with the aid of a light microscope. Only rat subjects with bilateral cannula placements within the borders of the $\mathrm{Ce}$ were included for statistical analyses.

Statistical analyses. TFLs collected from Ce-treated rats were analyzed in a three-factor ANOVA (intra-Ce drug treatment $\times$ systemic drug treatment $X$ time). Multiple pairwise comparisons were made using protected $t$ tests. Systemic drug treatment and time were analyzed as repeated measures.

\section{Results}

\section{Histology}

The bilateral placements of inner cannula tips corresponding to intra-amygdaloid lidocaine-treated rats $(n=7)$ are shown in Figure 9. Note that the cannula placements of these rats, as well as those corresponding to the intra-amygdaloid saline treated rats ( $n=7$; not shown in Fig. 9), were bilaterally within the borders of the $\mathrm{Ce}$.

\section{Nociceptive scores}

Figure 10 shows the TFLs of rats in Experiment 2. An ANOVA revealed a reliable interaction between intra-Ce drug treatment and systemic drug treatment $[F(1,12)=5.015, P<0.05]$, but no reliable main effect of time $[F(5,60)=1.39, P=0.24]$. Further analysis of the reliable interaction showed that there was no reliable difference between TFLs of systemic saline-treated rats simultaneously treated with intra-Ce lidocaine and systemic saline-treated rats simultaneously treated with intra-Ce saline (protected $t$ test, $P>0.05$ ). In rats treated with intra-Ce saline, morphine sulfate $(2.5 \mathrm{mg} / \mathrm{kg})$ produced a reliable elevation in TFLs as compared with systemic saline (Fig. 10; protected $t$ test, $P<0.01$ ), indicating reliable antinociception had occurred. The same dose of morphine produced reliably less antinociception, however, in rats treated with intra-Ce lidocaine (Fig. 10; protected $t$ test, $P<0.01$ ). The blockade of M $\Lambda$ by intra-Ce lidocaine was not complete, however, since morphine still retained reliable antinociceptive effects as compared with saline in lidocaine-treated rats (protected $t$ test, $P<0.05$ ).

\section{Experiment 3}

The results of Experiments 1 and 2 demonstrated that blockade of neural activity within the $\mathrm{Ce}$, using either a somata-selective excitotoxin or a nonspecific local anesthetic, abolishes the antinociceptive effects of $2.5 \mathrm{mg} / \mathrm{kg}$ morphine sulfate in the TF test. Experiment 3 was designed, therefore, to determine whether this effect is generalizable to other doses of systemic morphine.

\section{Materials and Methods}

Experiment 3 was identical to Experiment 1 except for the following: (1) only Ce-treated (sham lesion and lesion) rats were utilized, with each rat receiving four TF sessions (each separated by $7 \mathrm{~d}$ ) under four different systemic drug treatments $(0,2,4$, and $10 \mathrm{mg} / \mathrm{kg}$ morphine sulfate). Drug treatments were administered in a counterbalanced order within the Ce lesion and Ce sham-lesion groups. A stricter histological inclusion criterion of $90 \%$ bilateral damage was employed for Ce lesion rats since higher doses of morphine were being employed in this experiment as compared with the dose employed in Experiment 1.

Statistical analyses. TFLs collected from Ce-treated rats (lesion and sham lesion) were analyzed in a three-factor ANOVA (lesion $X$ systemic drug dose $\times$ time), with systemic drug dose and time analyzed as repeated measures. Multiple pairwise comparisons were made using protected $t$ tests.

\section{Results}

\section{Histology}

As observed in Experiment 1, all lesions had clearly definable borders. Lesions corresponding to rats in the Ce lesion group ( $n$ $=7$ ) are outlined in Figure 11. The dark shading in the figure indicates damaged tissue common to all rats in the group.

Of the 20 rats prepared for the Ce-lesion group in Experiment 3 , seven met the strict inclusion criterion of $90 \%$ bilateral $\mathrm{Ce}$ damage. Once again cases were rejected on the basis of insufficient bilateral $\mathrm{Ce}$ damage or sufficient damage to the $\mathrm{Ce}$ in only one hemisphere. In four of the seven Ce lesion cases, substantial neuronal cell loss was evident in all portions of the $\mathrm{Ce}$ (including the medial and lateral subdivisions) in both hemispheres. In another two cases, neuronal cell loss was evident in all portions of the $\mathrm{Ce}$ (including the medial and lateral subdivisions) in one hemisphere, and over $90 \%$ of the Ce in the other hemisphere. In the remaining case, neuronal cell loss was evident in over $90 \%$ of the Ce bilaterally. In all seven cases, neuronal damage extended dorsally into portions of overlying globus pallidus and caudate-putamen. Furthermore, in all seven cases there was substantial bilateral damage to the BL and portions of the lateral nucleus, in addition to varying amounts of bilateral damage to the intra-amygdaloid division of the bed nucleus of the stria terminalis, the Me and the basomedial amygdaloid nucleus. 


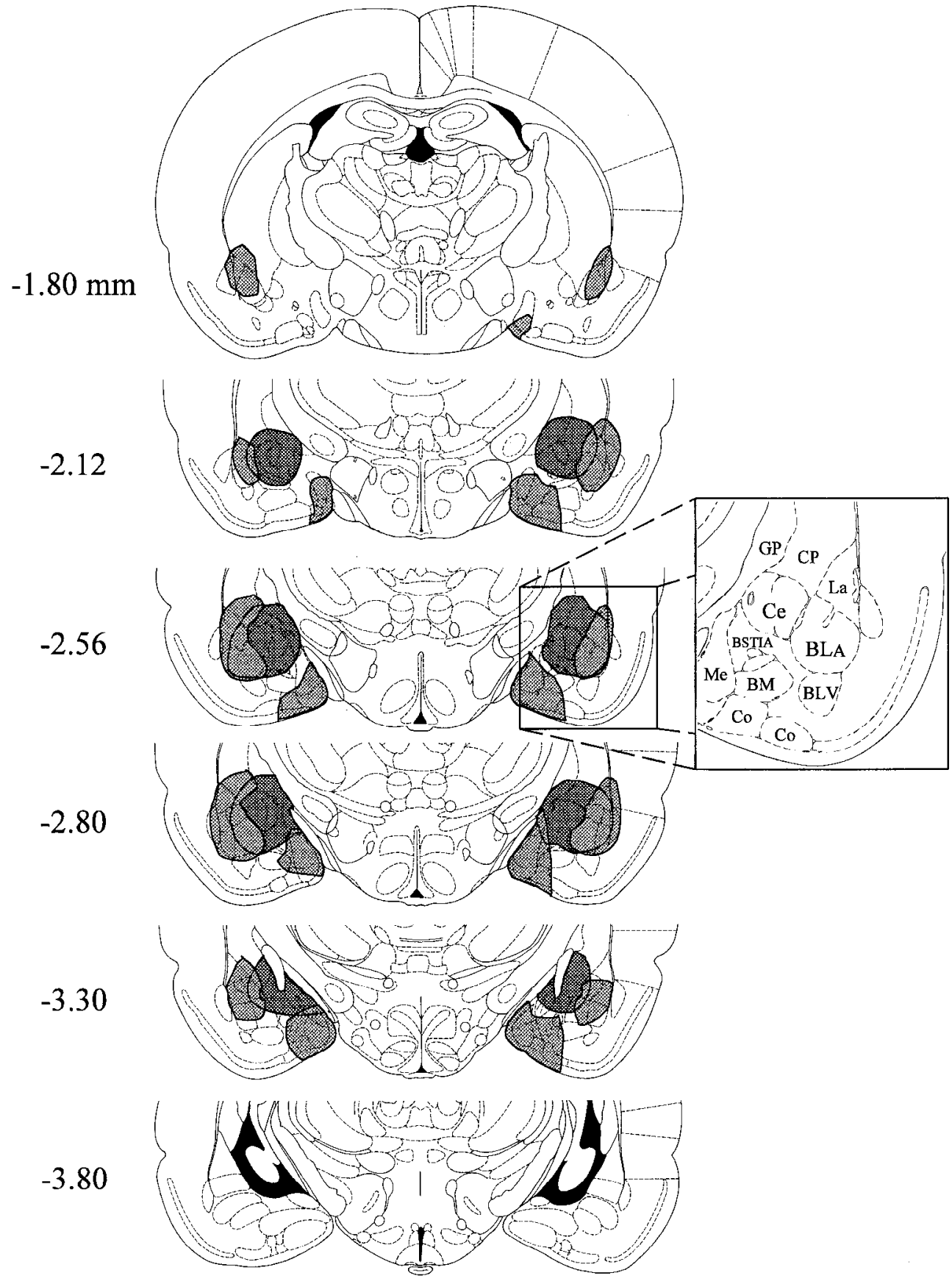

Figure 8. Combined histological results of Experiment 1 (bilateral $\mathrm{Me}, \mathrm{Ce}$, and $\mathrm{BL}$ lesions). The histological results depicted in Figures 2, 4, and 6 are combined into a composite representation of the bilateral lesions that resulted in reliable attenuation of morphine antinociception (Ce lesions; see Fig. 3) and the bilateral lesions that failed to attenuate morphine antinociception (BL and Me lesions; see Figs. 5 and 7 , respectively). Millimeters posterior to bregma are given to the left. The bilateral dark shading indicates lesion area common to all rats in the Ce lesion group of Experiment 1. Lesion area common to rats in the BL and Me lesion groups is shown as light shading in each hemisphere. Note that while bilateral $\mathrm{Ce}$ lesions also consistently resulted in substantial neuronal cell loss in the BL, Me and lateral anygdaloid nucleus, this damage was largely controlled for in the BL and Me lesion groups. Adapted from Paxinos and Watson (1986). Amygdaloid areas: $C e$, central nucleus; $B L A$, basolateral nucleus, anterior; $B L V$, basolateral nucleus, ventral; BSTIA, bed nucleus of the stria terminalis, intra-amygdaloid division: $M e$, medial nucleus; $B M$, basomedial nucleus; $C o$, cortical amygdaloid nuclei: Extra-amygdaloid areas: $G P$, globus pallidus; $C P$, caudate-putamen.
No lesion rats showed any signs of neuronal cell loss or gliosis when examined along the rostral-caudal extent of the PAG.

\section{Nociceptive scores}

TFLs of Ce-treated rats (lesion and sham lesion) are shown in Figure 12. An ANOVA revealed reliable interactions between lesion and systemic drug dose $[F(3,42)=11.62, P<0.0001]$, lesion and time $[F(5,70)=3.51, P<0.01]$ and systemic drug dose and time $[F(15,210)=3.28, P<0.0001]$. Further analysis of the lesion $X$ systemic drug dose interaction showed that morphine sulfate $(2,4$ and $10 \mathrm{mg} / \mathrm{kg})$ produced dose-dependent antinociception in Ce sham-lesion rats (Fig. 12A; protected $t$ tests, $P<0.01$ ). The two lower doses of morphine sulfate ( 2 and 4 $\mathrm{mg} / \mathrm{kg}$ ), however, failed to produce reliably higher TFLs than saline in Ce lesion rats (Fig. 12B; protected $t$ tests, $P>0.05$ ).
The highest dose of morphine sulfate $(10 \mathrm{mg} / \mathrm{kg})$ did produce reliable antinociception in Ce lesion rats (Fig. 12B; protected $t$ test, $P<0.05$ ) but this effect was reliably lower than that produced by $10 \mathrm{mg} / \mathrm{kg}$ morphine sulfate in Ce sham-lesion rats (Fig. $12 A$; protected $t$ test, $P<0.05$ ). Finally, as was the case in Experiment 1, the TFLs of Ce lesion rats treated with saline were not reliably different from TFLs displayed by Ce shamlesion rats treated with saline (Fig. 12; protected $t$ test, $P>$ $0.05)$.

\section{Experiment 4}

The results of Experiments 1-3 suggest that the Ce contributes to the production of $\mathrm{MA}$ in the TF test. It could be argued, however, that blockade of neural activity within the Ce increases a rat's sensitivity to noxious stimulation (i.e., produces hyper- 
Figure 9. Histological results of Experiment 2 (bilateral lidocaine injections into the $\mathrm{Ce}$ ). Representations of four coronal sections through the rat anygdala are shown in sequence from anterior to posterior. Millimeters posterior to bregma are given to the left. The solid circles in each hemisphere show the approximate positions of the cannula tips corresponding to rats in the intra-Ce lidocaine treatment group $(n=7)$. Adapted from Paxinos and Watson (1986). Amygdaloid areas: $C e$, central nucleus; $B L A$, basolateral nucleus, anterior; $B L V$, basolateral nucleus, ventral; BSTIA, bed nucleus of the stria terminalis, intra-amygdaloid division; $M e$, medial nucleus; $B M$, basomedial nucleus; $C o$, cortical annygdaloid nuclei. Extra-amygdaloid areas: $G P$, globus pallidus; $C P$, caudate-putamen.

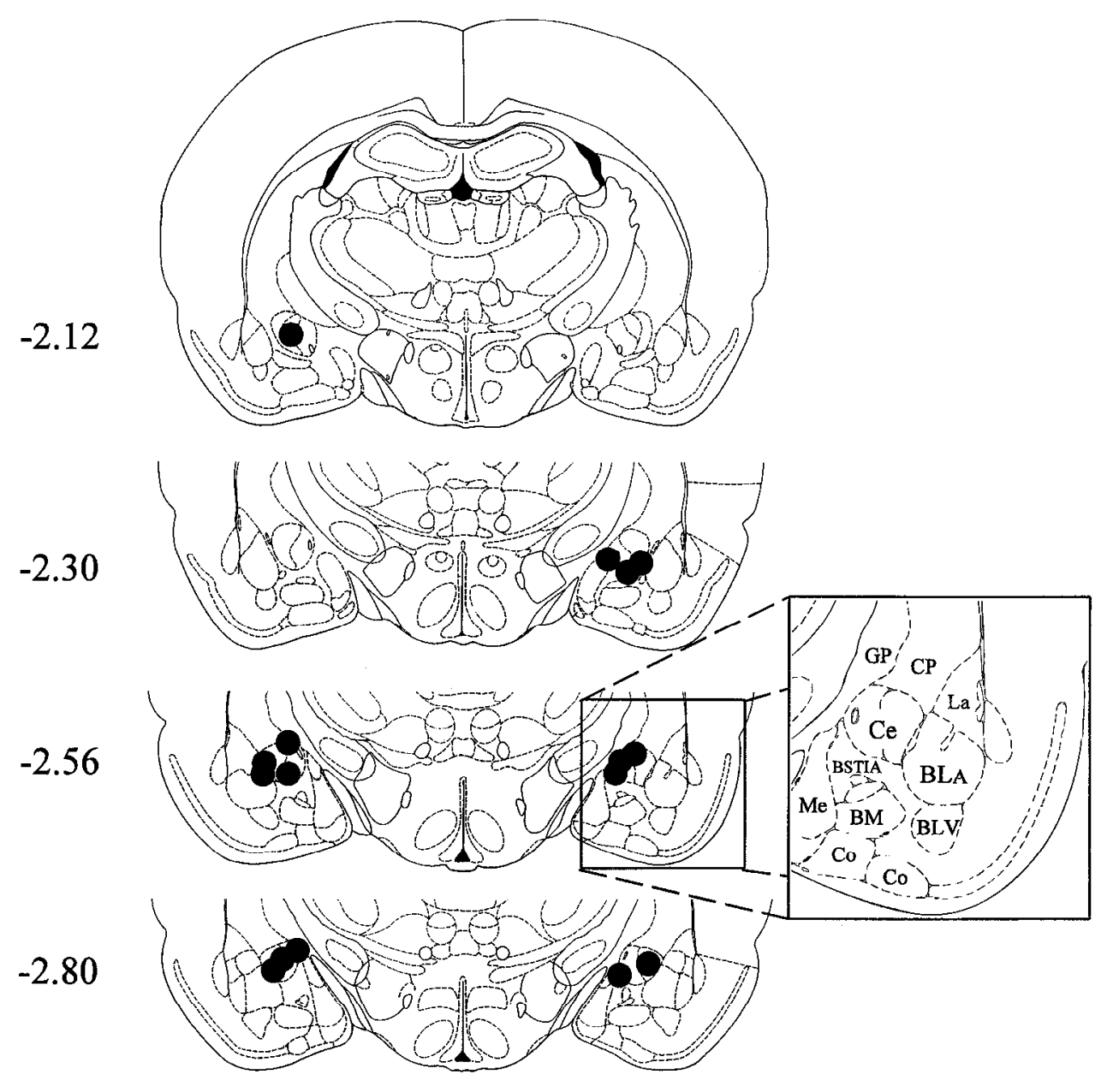

algesia) independent of a disruption of pain control circuitry. This increase in sensitivity, in turn, could result in a rightward shift in the morphine dose-response curve. While $\mathrm{Ce}$ blockade appeared to have had no hyperalgesic effect on baseline TFLs in Experiments 1-3 (Figs. 3, 10, 12), this possibility cannot be entirely discounted since baseline TFLs of 3-4 sec are not particularly sensitive for detection of hyperalgesia (Hargreaves et al., 1988). It remains possible, then, that the effects observed in Experiments 1-3 reflect a hyperalgesic effect of Ce lesions, and not a disruption of antinociceptive mechanisms. To thoroughly investigate this possibility, another set of Ce-treated rats (lesion and sham lesion) was prepared and tested for nociceptive reactivity with the heat source adjusted to result in baseline TFLs of 10-12 sec. Similar latencies have been used for sensitive detection of hyperalgesia using the paw-withdrawal test (Hargreaves et al., 1988; Mao et al., 1994). All rats received TF test sessions on each of 6 weeks following surgery to test for possible timedependent effects of Ce lesions on baseline TFLs.

\section{Materials and Methods}

Experimental design. One set of Ce-treated (lesion and sham lesion) rats was surgically prepared as described in Experiment 1. Animals were allowed to recover for $7 \mathrm{~d}$ before nociceptive testing began. The gencral procedurc of TF testing applied to these rats was similar to the procedure described in Experiment 1, with the following differences: (1) each animal received six nociceptive test sessions (see below), with each test session separated by $7 \mathrm{~d}$; (2) each of these test sessions, in turn, consisted of three TF trials only, the results of which were averaged to result in a single nociceptive score for that session; (3) the heat source was adjusted to result in baseline TFLs of 10-12 sec. Histological procedures and lesion mapping were similar to those described in Experiment 1, with an inclusion criterion of $80 \%$ bilateral Ce damage applied to Ce lesion rats.

Nociceptive testing. Nociceptive test procedures were similar to those described in Experiments 1 and 2, with the following differences. Once again, each rat was positioned in a plastic restrainer, to which the rat was habituated for $1 \mathrm{hr}$ on each of $3 \mathrm{~d}$ prior to testing. The radiant heat source (described in Experiment 1) was aimed at the caudal end (4-10 $\mathrm{cm}$ from the tail tip) of the rat's tail and adjusted by a rheostat to result in baseline TFLs of 10-12 sec. An automatic cutoff time of $15 \mathrm{sec}$ was preset to minimize possible tissue damage caused by overstimulation in the absence of a withdrawal response. For each test session, three TF trials were made with a 3 min intertrial interval, and with changes in the position of the tail receiving heat stimulation on each trial. The mean TFL from the three trials was used as the nociceptive score for that test session.

Statistical analyses. TFLs collected from Ce-treated rats were analyzed in a two-factor ANOVA (lesion $\times$ week), with week analyzed as a repeated measure. Multiple pairwise comparisons were then made using protected $t$ tests.

\section{Results}

Histology

Of the 20 rats prepared for the Ce lesion group in Experiment 4 , nine met the inclusion criterion of $80 \%$ bilateral Ce damage. The lesions of these nine rats were similar in size to those shown in Figure 2.

\section{Nociceptive scores}

TFLs were consistently lower in Ce lesion rats $(n=9)$ as compared with Ce sham-lesion rats $(n=11)$ at all weeks tested (Fig. 


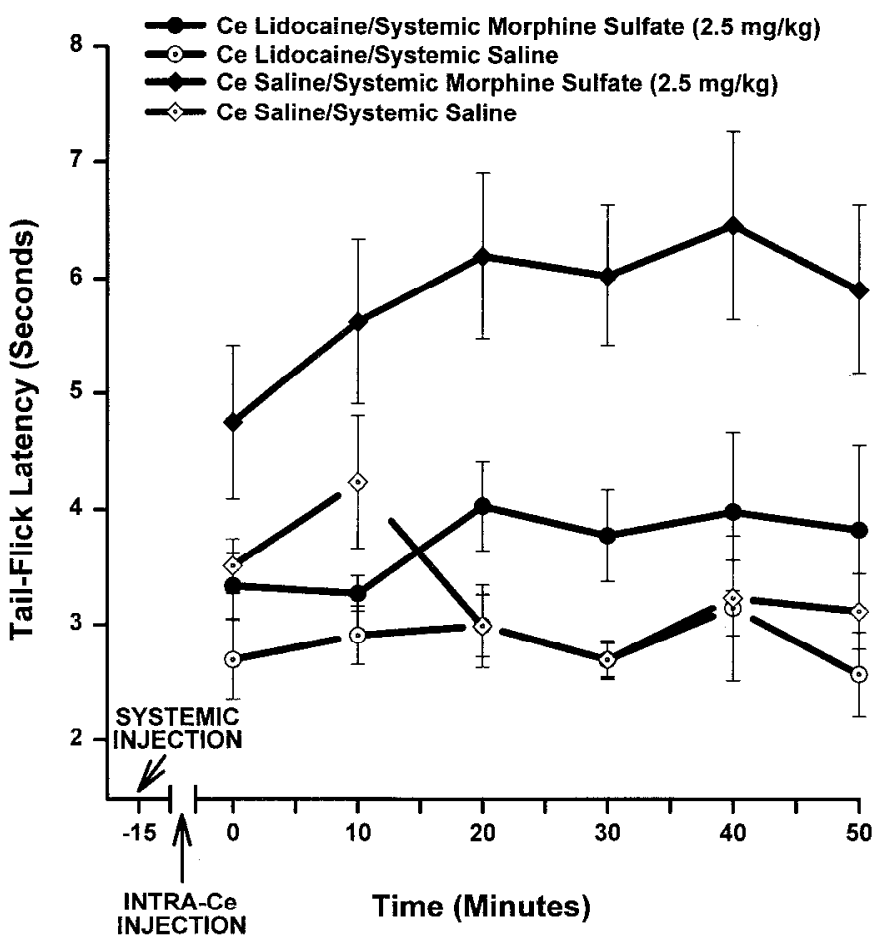

Figure 10. Mean TF latencies of intra-Ce lidocaine $(n=7)$ and intraCe saline $(n=7)$ treated rats in Experiment 2. Error bars indicate SEM. In rats treated with bilateral intra-Ce microinjections of saline, systemic administration of morphine sulfate $(2.5 \mathrm{mg} / \mathrm{kg}$, s.c. $)$ resulted in reliable elevation of TF latencies (i.e., antinociception) as compared with systemic administration of saline (protected $t$ test, $P<0.01$ ). Morphine sulfate $(2.5 \mathrm{mg} / \mathrm{kg}$, s.c.) also produced reliable antinociception in rats treated with bilateral intra-Ce microinjections of lidocaine (protected $t$ test, $P<0.05$ ), but this effect was reliably lower than that produced by the same dose of morphine in rats treated with intra-Ce saline. $\mathrm{Bi}-$ lateral intra-Ce microinjection of lidocaine failed to alter baseline (i.e., systemic saline) TF latencies as compared with bilateral intra-Ce microinjection of saline (protected $t$ test, $P>0.05$ ). Note that bilateral intra-Ce microinjection of lidocaine reliably attenuated MA for the entire duration of the $50 \mathrm{~min}$ test session (protected $t$ test, $P<0.05$ ). This duration of effect appears to be consistent with the time course of neuronal inactivation and hypometabolism produced by lidocaine in the cerebral cortex (Sandkühler et al., 1987) and spinal cord dorsal columns (Martin, 1991).

13). This effect, however, cannot be classified as reliable thermal hyperalgesia since there was no reliable main effect of lesion $[F(1,20)=2.41, P>0.05]$, nor was there a reliable interaction between lesion and week $[F(5,100)=0.936, P>0.05]$. Given that $\mathrm{Ce}$ lesion rats in Experiments 1 and 3 were tested at $1-4$ weeks after surgery, it seems unlikely that the results of these experiments were artifacts of Ce lesion-induced hyperalgesia.

\section{Discussion}

The results of Experiments $1-4$ indicate that bilateral lesions of the $\mathrm{Ce}$ abolish the antinociceptive effects of low doses $(2,2.5$, $4 \mathrm{mg} / \mathrm{kg}$ ) of systemically administered morphine in the rat TF test (Figs. 3, 10, 12). Antinociception can be partially reinstated, however, if the dose of morphine sulfate is raised to $10 \mathrm{mg} / \mathrm{kg}$ (Fig. 12B). This pattern of results is similar to patterns obtained with thoracic spinal cord transections (Advokat and Burton, 1987), bilateral lesions of the spinal cord DLF (Basbaum et al., 1977), and lesions of the rostral ventromedial medulla (Yaksh et al., 1977): the inhibitory effects of these manipulations on MA can be overcome if the dose of morphine sulfate is raised from $3-5 \mathrm{mg} / \mathrm{kg}$ to $10+\mathrm{mg} / \mathrm{kg}$. The apparent antinociceptive effect of $10 \mathrm{mg} / \mathrm{kg}$ in Ce lesion rats (Fig. 12B) may indeed reflect reinstatement of antinociccption, perhaps through an increased contribution of spinal cord or peripheral (e.g., Levine and Taiwo, 1989) sites of action as the dose of systemic morphine is raised. Alternatively, increased motor impairments (i.e., catatonia) that accompany higher doses of morphine (De Ryck et al., 1980; Wolgin, 1985), or the few surviving Ce neurons that remained in several Ce lesion rats, may account for the apparent presence of an antinociceptive effect at this dose.

It is unlikely that a factor other than the destruction of $\mathrm{Ce}$ neurons was responsible for the attenuation of MA in the present experiments. First, biochemical analyses of the effects of NMDA lesions in other brain areas indicate that this neurotoxin leaves fibers of passage intact (Hastings et al., 1985; Winn et al., 1990, 1991). It is unlikely, then, that damage to fibers coursing through or around the $\mathrm{Ce}$ is responsible for the effects reported in the present experiments. Second, while our Ce lesions also extended into the basolateral, lateral, and medial amygdaloid nuclei, the effects of this extraneous damage were controlled for in the BL and Me lesion groups of Experiment 1 (see Fig. 8). Third, it is unlikely that neuronal damage to portions of overlying striatum and globus pallidus account for the present effects since well over $95 \%$ of both structures remained intact in Ce lesion rats. Finally, the techniques used to block Ce neuronal activity in Experiments 1 and 2 are complementary: the somata-selective lesions produced by NMDA infusion control for the blockade of fiber activity produced by lidocaine infusion, and the nonselective local anesthesia produced by lidocaine infusion controls for possible remote, seizure-induced damage produced by NMDA infusion.

The present experiments are the first to demonstrate that lesions of a specific amygdaloid nucleus disrupt MA in the TF test. Several other reports, however, implicate the amygdala in MA. We have recently shown that the suppression of formalininduced nociceptive behaviors by systemically administered morphine is strongly attenuated by bilateral excitotoxin-induced lesions of the Ce (Manning and Mayer, 1995). Furthermore, microinjection of morphine into the corticomedial subdivision of the amygdala has been reported to produce antinociception in the flinch-jump (Rodgers, 1977, 1978) and hot plate (Yaksh et al., 1988) tests, and one report suggests that microinjection of morphine into the BL produces antinociception in the TF test (Helmstetter et al., 1993). While the BL and corticomedial amygdaloid subdivision may indeed elicit antinociception upon focal microinjection of morphine, the results of Experiment 1 (Fig. 8) suggest that these areas are not major contributors to the antinociceptive effects of systemic morphine, since large bilateral lesions of the $\mathrm{Me}$ (including large portions of the cortical amygdaloid nuclei; see Figs. 6, 8) or BL (Figs. 4, 8; see also Manning and Mayer, 1995) do not attenuate MA (Figs. 5, 7).

Our present and previous (Manning and Mayer, 1995) data suggest that the $\mathrm{Ce}$ contributes to the production of MA in both the formalin and TF tests. This pattern of results, however, contrasts somewhat with several previously published reports. In agreement with our previous data, removal of the entire rat forebrain (i.e., decerebration) is reported to attenuate the antinociceptive effects of systemic morphine in the formalin test (Matthies and Franklin, 1992). Decerebration does not, however, similarly impair MA in the TF test (Proudfit and Levy, 1978; Matthies and Franklin, 1992). These results appear to support the hypothesis that the neural substrates underlying MA in the for- 
Figure 11. Histological results of Experiment 3 (bilateral Ce lesions). Representations of six coronal sections through the rat forebrain are shown in sequence from anterior to posterior. Millimeters posterior to bregma are given to the left. The closed curves illustrate the borders of Ce lesions ( $n=$ 7), as determined by the extent of neuronal cell loss and gliosis. Lesion area common to all seven rats is shown as dark shading in each hemisphere. Adapted from Paxinos and Watson (1986). Anngdaloid areas: $C e$, central nucleus; $B L A$, basolateral nucleus, anterior; $B L V$, basolateral nucleus, ventral; BSTIA, bed nucleus of the stria terminalis, intra-amygdaloid division; $M e$, medial nucleus; $B M$, basomedial nucleus; $C o$, cortical amygdaloid nuclei. Extra-amygdaloid areas: $G P$, globus pallidus; $C P$, caudate-putamen.

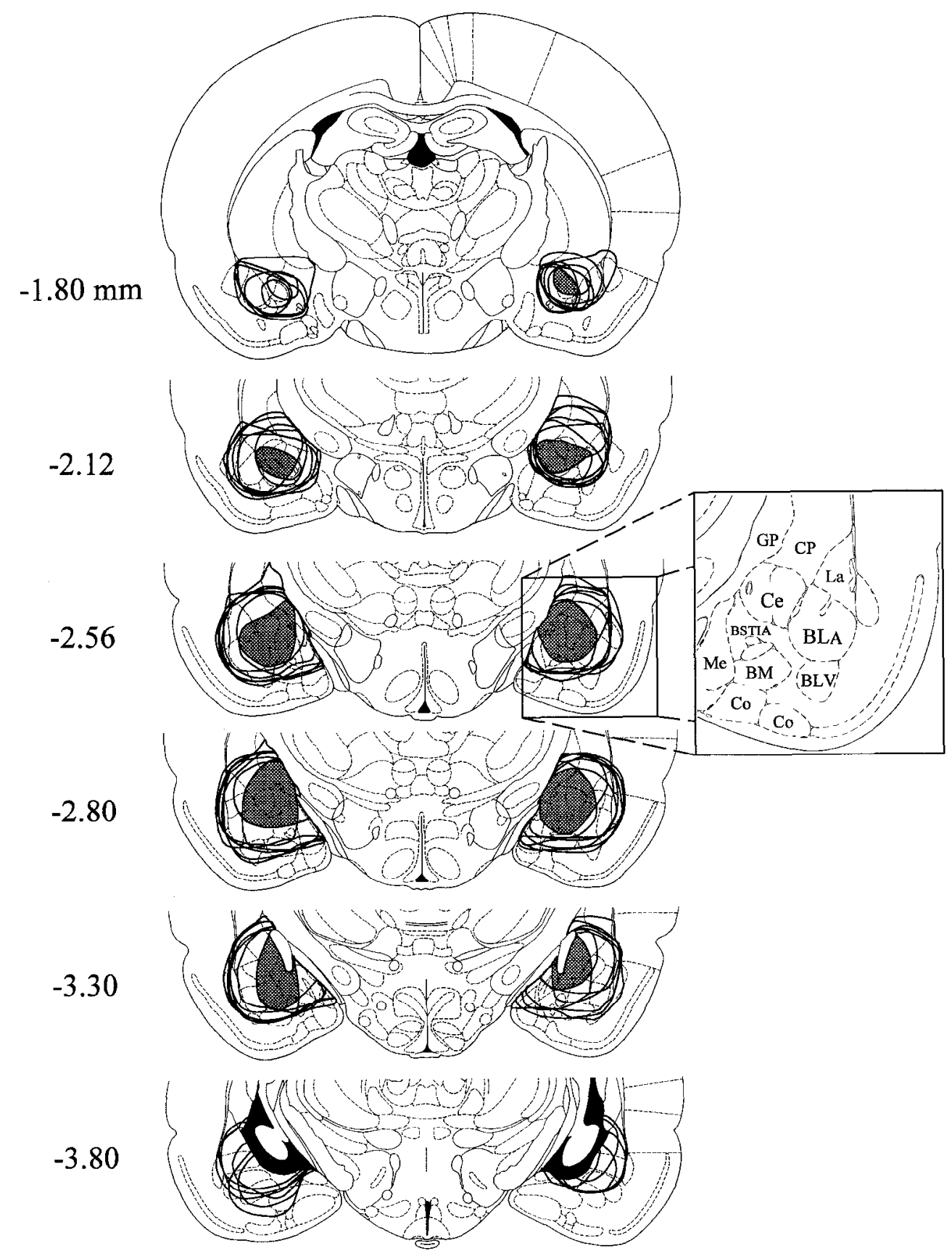

malin test are different from those underlying MA in the TF test (e.g., Abbott and Melzack, 1982). Our data tend to suggest, however, that the neural substrates underlying MA in the formalin and TF tests overlap, at least at the level of the amygdala. Clear$1 y$, further experimentation is necessary to determine why discrete bilateral removal of the $\mathrm{Ce}$ using an excitotoxin is effective in attenuating MA in the TF test (present results), while gross bilateral removal of the $\mathrm{Ce}$ via decerebration fails to have a similar effect (Proudfit and Levy, 1978; Matthies and Franklin, 1992).

It remains unclear as to which subpopulation of $\mathrm{Ce}$ receptors plays a role in MA. If opioid receptors within the $\mathrm{Ce}$ are necessary, then systemically administered morphine may elicit at least part of its antinociceptive effects through direct action at these receptors. Two lines of evidence, however, count against this possibility. First, receptor autoradiographic studies have failed to detect the presence of $\mu$-opioid receptors in the $\mathrm{Ce}$ (McLean et al., 1986; Mansour et al., 1987). Second, intra-Ce microinjection of morphine appears to be ineffective in eliciting antinociception in the flinch-jump and TF tests (Rodgers, 1978). Although further research is necessary to determine the precise role of the $\mathrm{Ce}$ in $\mathrm{MA}$, the possibility exists that the Ce represents a nonopioid component of endogenous antinociceptive circuitry that is activated after the occupation of opioid receptors elsewhere in the CNS.

In addition to its putative role in MA, several other lines of evidence suggest an involvement of the anygdala in antinociceptive processes. Bilateral microinjection of carbachol into various amygdaloid nuclei, including the $\mathrm{Ce}$, has been reported to elicit antinociception in the TF test (Klamt and Prado, 1991; 

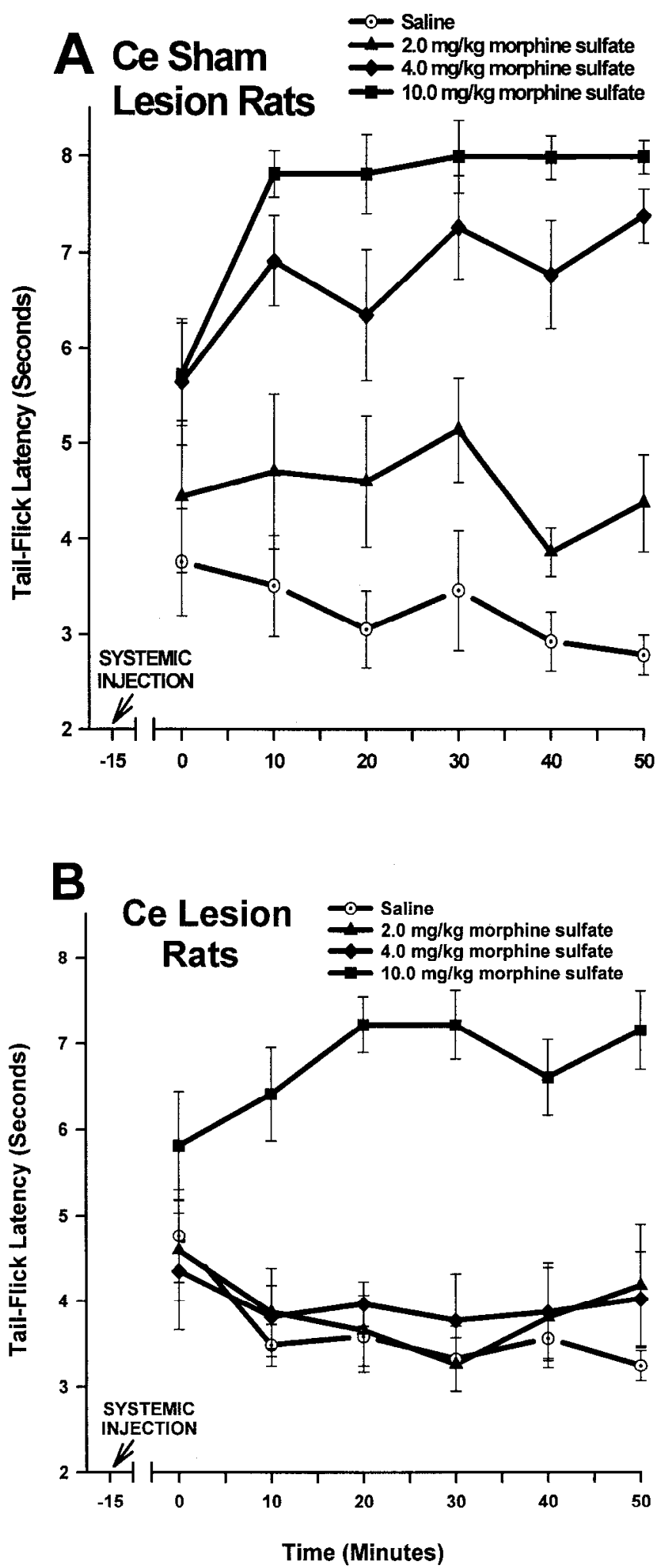

Figure 12. Mean TF latencies of Ce sham-lesion $(A ; n=8)$ and $\mathrm{Ce}$ lesion $(B ; n=7)$ rats in Experiment 3. Error bars indicate SEM. Baseline (i.e., systemic saline) TF latencies of Ce lesion rats were not reliahly different from those of Ce sham-lesion rats (protected $t$ test, $P>0.05$ ). In $\mathrm{Ce}$ sham-lesion rats, morphine sulfate $(2,4$ and $10 \mathrm{mg} / \mathrm{kg}$, s.c.) produced dosedependent antinociception (see $A$ and Experiment 3, Results). In Ce lesion rats, however, 2 and $4 \mathrm{mg} / \mathrm{kg}$ morphine sulfate failed to produce reliable antinociception ( $B$; protected $t$ test, $P>0.05$ ). A dose of $10 \mathrm{mg} / \mathrm{kg}$ produced reliable antinociception in Ce lesion rals $(B$; protected $t$ test, $P<$ 0.05 ), but the antinociception was reliably less than that produced by the same dose in Ce sham-lesion rats (protected $t$ test, $P<0.05$ ).

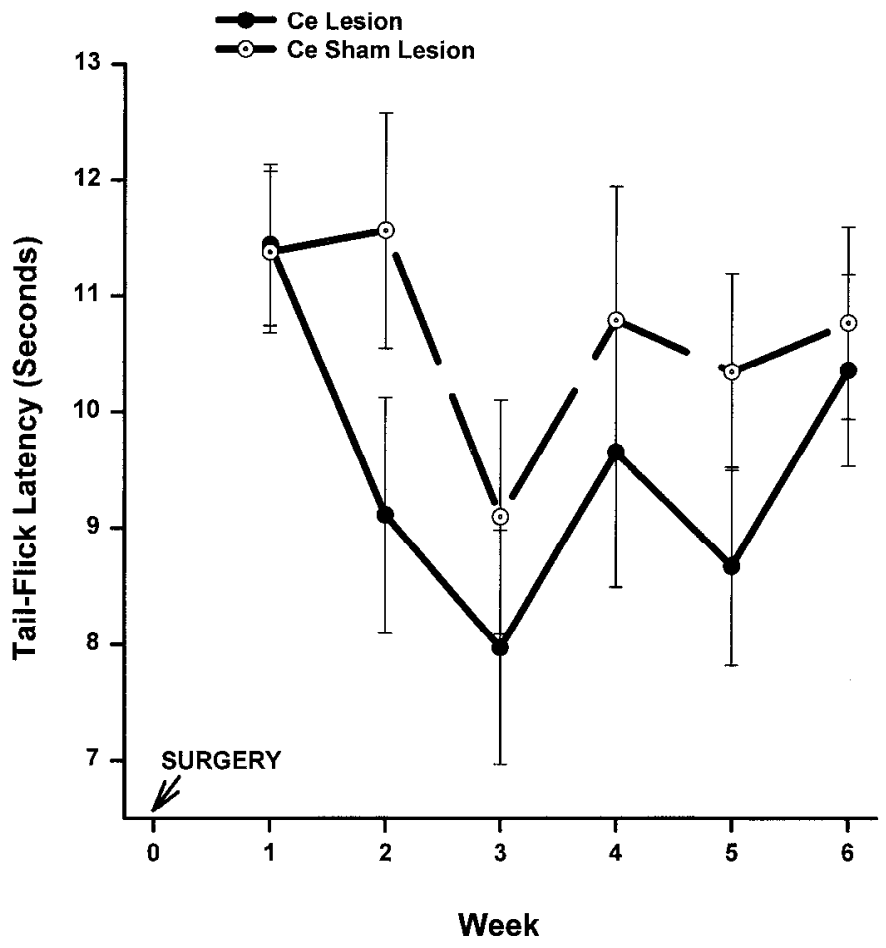

Figure 13. Mean TF latencies of Ce sham-lesion $(n=11)$ and $\mathrm{Ce}$ lesion $(n=9)$ rats in Experiment 4 . Error bars indicate SEM. The heat source was adjusted in this experiment to result in baseline TF latencies of $10-12 \mathrm{sec}$. This was done in order to better detect a possible hyperalgesic effect of Ce lesions. Although the Ce lesion group displayed consistently lower mean TF latencies than the Ce sham-lesion group, TF latencies of Ce lesion rats were not reliably different from those of Ce sham-lesion rats (protected $t$ test, $P>0.05$ ). These results suggest that bilateral Ce lesions fail to result in reliable thermal hyperalgesia.

Oliveira and Prado, 1994), while bilateral intra-Ce microinjection of the enkephalinase inhibitor SCH-32615 (Al-Rodhan et al., 1990) or neurotensin (Kalivas et al., 1982) elicits antinociception in the hot plate test. Several recent reports also implicate the amygdala in the expression of several forms of environmentally induced antinociception. Bilateral lesions of the amygdala (including the $\mathrm{Ce}$ ) abolish antinociception produced by reexposure to cues previously associated with noxious footshock (i.e., classically conditioned antinociception; Helmstetter, 1992; Helmstetter and Bellgowan, 1993; Watkins et al., 1993). Lesions of the Ce also impair some unconditioned forms of environmentally induced antinociception in the TF test. The antinociception produced by exposure to a natural predator (Fox and Sorenson, 1994), as well as the antinociceptions produced by exposure to brief (Fox and Sorenson, 1994) or prolonged (Werka and Marek, 1990; Werka, 1994) footshock, are all attenuated or abolished by bilateral Ce lesions.

The amygdala, PAG, and hypothalamus have been proposed to be components of an integrated defense system (Adams, 1979; Graeff, 1988; LeDoux et al., 1988; Fanselow, 1991; Helmstetter, 1992). Furthermore, the amygdala (including the (e) has been repeatedly implicated in the mediation of both conditioned and innate fear-related processes (see Davis, 1992, for a revicw). A role for the $\mathrm{Ce}$ in antinociceptive processes (including MA) is not inconsistent with its proposed role in fear and defense reactions; indeed, classically conditioned antinociception is considered to be an index of fear by some investigators (Lichtman and Fanselow, 1991; Helmstetter, 1992). It 
may also be relevant that the Ce receives nociceptive signals from the parabrachial area via the spino-ponto-amygdaloid nociceptive pathway (Bernard et al., 1992). These signals have been hypothesized to trigger affective-motivational responses to noxious stimulation (Bernard and Besson, 1990; Bernard et al., 1992), responses that may, under certain circumstances, include fear and antinociception. It may be useful, then, to view the amygdala as part of a highly complex and coordinated defense system of which nociception, fear, antinociception (both conditioned and unconditioned) and various autonomic concomitants are all components.

The present results are the first to demonstratc, using lesioning techniques, that relatively low doses of systemically administered morphine require the integrity of a specific forebrain area to suppress nociceptive signals at the level of the spinal cord. While microinjections of various opioid and nonopioid compounds into a wide range of brainstem and forebrain areas have been shown to elicit antinociception, only lesions of the spinal cord DLF (e.g., Basbaum et al., 1977; Hayes et al., 1978; Barton et al., 1980) and medullary nucleus raphe magnus (e.g., Proudfit and Anderson, 1975; Cannon et al., 1983) have consistently resulted in attenuation of the antinociceptive effects of systemic morphine. Accordingly, a large portion of the research into supraspinal pain control systems has focussed on medullospinal systems (see Fields et al., 1991). Given, however, that there is now mounting evidence implicating the amygdala in the production of MA, as well as several forms of conditioned and unconditioned environmentally induced antinociception, it may be appropriate to incorporate the amygdala into current models of endogenous pain control circuitry. At the very least, further experimentation is necessary to determine how the Ce interacts with previously established pain control circuitry to generate the full antinociceptive effect of systemic morphine.

\section{References}

Abbott FV, Melzack R (1982) Brainstem lesions dissociate neural mechanisms of morphine analgesia in different kinds of pain. Brain Res 251:149-155.

Adams DB (1979) Brain mechanisms for offense, defense and submission. Behav Brain Sci 2:201-241.

Advokat C, Burton P (1987) Antinociceptive effect of systemic and intrathecal morphine in spinally transected rats. Eur J Pharmacol 139: 335-343.

Al-Rodhan N, Chipkin R, Yaksh TL (1990) The antinociceptive effects of SCH-32615, a neutral endopeptidase (enkephalinase) inhibitor, microinjected into the periaqueductal, ventral medulla and amygdala. Brain Res 520:123-130.

Barton C, Basbaum AI, Fields HL (1980) Dissociation of supraspinal and spinal actions of morphine: a quantitative evaluation. Brain Res 188:487-498.

Basbaum AI, Fields HL (1978) Endogenous pain control mechanisms: review and hypothesis. Ann Neurol 4:451-462.

Basbaum AI, Fields HL (1984) Endogenous pain control systems: brainstem spinal pathways and endorphin circuitry. Annu Rev Neurosci 7:309-338.

Basbaum AI, Marley NJE, O'Keefe J, Clanton CH (1977) Reversal of morphine and stimulus-produced analgesia by subtotal spinal cord lesions. Pain 3:43--56.

Beitz AJ (1982) The organization of afferent projections to the midbrain periaqueductal gray of the rat. Neuroscience 7:133-159.

Ben-Ari Y, Tremblay E, Ottersen OP, Naquet R (1979) Evidence suggesting secondary epileptogenic lesions after kainic acid: pretreatment with diazcpam reduces distant but not local brain damage. Brain Res 165:362-365.

Bernard JF, Besson JM (1990) The spino(trigemino)pontoamygdaloid pathway: electrophysiological evidence for an involvement in pain processes. J Neurophysiol 63:473-490.

Bernard JF, Huang GF, Besson JM (1992) Nucleus centralis of the amygdala and the globus pallidus ventralis: electrophysiological evidence for an involvement in pain processes. J Neurophysiol 68:551569.

Cannon JT, Lewis JW, Weinberg VE, Liebeskind JC (1983) Evidence for the independence of brainstem mechanisms mediating analgesia induced by morphine and two forms of stress. Brain Res 269:231236.

d'Amore A, Lorenzini P, Massotti M (1991) Antinociceptive action of opiates and opioid peptides after unilateral microinjection into area tempestas in rats. J Pharmacol Exp Ther 259:1308-1315.

D'Amour FE, Smith DL (1941) A method for determining loss of pain sensation. J Pharmacol Exp Ther 72:74-79.

Davis M (1992) The role of the amygdala in conditioned fear. In: The amygdala: neurobiological aspects of emotion, memory, and mental dysfunction (Aggleton JP, ed), pp 255-305. New York: Wiley-Liss.

Depaulis A, Morgan MM, Liebeskind JC (1987) GABAergic modulation of the analgesic effects of morphine microinjected in the ventral periaqueductal gray matter of the rat. Brain Res 436:223-228.

De Ryck M, Schallert T, Teitelbaum P (1980) Morphine versus haloperidol catalepsy in the rat: a behavioral analysis of postural support mechanisms. Brain Res 201:143-172.

Dubuisson D, Dennis SG (1977) The formalin test: a quantitative study of the analgesic effects of morphine, meperidine and brain stem stimulation in rats and cats. Pain 4:161-174.

Fanselow MS (1991) The midbrain periaqueductal gray as a coordinator of action in response to fear and anxiety. In: The midbrain periaqueductal gray matter: functional, anatomical, and neurochemical organization (Depaulis A, Bandler R, eds), pp 151-173. Ncw York: Plenum.

Fields HL, Heinricher MM, Mason P (1991) Neurotransmitters in nociceptive modulatory circuits. Annu Rev Neurosci 14:219-245.

Fox RJ, Sorenson CA (1994) Bilateral lesions of the amygdala attenuate analgesia induced by diverse environmental challenges. Brain Res 648:215-221.

Graeff FG (1988) Animal models of aversion. In: Selected models of anxiety, depression and psychosis (Simon P, Soubrié P, Wildlocher D, eds), pp 115-141. Basel: Karger.

Hargreaves K, Dubner R, Brown F, Flores C, Joris J (1988) A new and sensitive method for mcasuring thermal nociception in cutaneous hyperalgesia. Pain 32:77-88

Hastings MH, Winn P, Dunnett SB (1985) Neurotoxic amino acid lesions of the lateral hypothalamus: a parametric comparison of the effects of ibotenate, $N$-methyl-D,L-aspartate and quisqualate in the rat. Brain Res 360:248-256.

Hayes RL, Price DD, Bennett GJ, Wilcox GL, Mayer DJ (1978) Differential effects of spinal cord lesions on narcotic and non-narcotic suppression of nociceptive reflexes: further evidence for the physiologic multiplicity of pain modulation. Brain Res 155:91-101.

Helmstetter FJ (1992) The amygdala is essential for the expression of conditional hypoalgesia. Behav Neurosci 106:518-528.

Helmstetter FJ, Bellgowan PS (1993) Lesions of the amygdala block conditional hypoalgesia on the tail flick test. Brain Res 612:253-257.

Helmstetter FJ, Bellgowan PS, Tershner SA (1993) Inhibition of the tail flick reflex following microinjection of morphine into the amygdala. Neuroreport 4:471-474.

Hopkins DA, Holstege G (1978) Amygdaloid projections to the mesencephalon, pons and medulla oblongata in the cat. Exp Brain Res 32:529-547.

Jensen TS, Yaksh TL (1986a) I. Comparison of antinociceptive action of morphine in the periaqueductal gray, medial and paramedial medulla in rat. Brain Res 363:99-113.

Jensen TS, Yaksh TL (1986b) II. Examination of spinal monoamine receptors through which brainstem opiate-sensitive systems act in the rat. Brain Res 363:114-127.

Kalivas PW, Gau BA, Nemeroff CB, Prange AJ Jr (1982) Antinociception after microinjection of neurotensin into the central amygdaloid nucleus of the rat. Brain Res 243:279-286.

Klamt JG, Prado WA (1991) Antinociception and behavioral changes induced by carbachol microinjected into identified sites of the rat brain. Brain Res 549:9-18.

Köhler C, Schwarcz R (1983) Comparison of ibotenate and kainate neurotoxicity in rat brain: a histological study. Neuroscience 8:819835.

LeDoux JE, Iwata J, Cicchetti P, Reis DJ (1988) Different projections 
of the central amygdaloid nucleus mediate autonomic and behavioral correlates of conditioned fear. J Neurosci 8:2517-2529.

Levine JD, Taiwo YO (1989) Involvement of the mu-opiate receptor in peripheral analgesia. Neuroscience 32:571-575.

Lichtman AH, Fanselow MS (1991) Opioid and nonopioid conditional analgesia: the role of spinal opioid, noradrenergic and serotonergic systems. Behav Neurosci 105:687-698.

Manning BH, Mayer DJ (1995) The central nucleus of the amygdala contributes to the production of morphine antinociception in the formalin test. Pain 63:141-152.

Manning BH, Morgan MJ, Franklin K (1994) Morphine analgesia in the formalin test: evidence for forebrain and midbrain sites of action. Neuroscience 63:289-294.

Mansour A, Khachaturian H, Lewis ME, Akil H, Watson SJ (1987) Autoradiographic differentiation of mu, delta and kappa opioid receptors in the rat forebrain and midbrain. J Neurosci 7:2445-2464.

Mao J, Price DD, Mayer DJ (1994) Thermal hyperalgesia in association with the development of morphine tolerance in rats: roles of excitatory amino acid receptors and protein kinase C. J Neurosci 14: 2301-2312.

Martin JH (1991) Autoradiographic estimation of the extent of reversible inactivation produced by microinjection of lidocaine and muscimol in the rat. Neurosci Lett 127:160-164.

Matthies BK, Franklin K (1992) Formalin pain is expressed in decerebrate rats but not attenuated by morphine. Pain 51:199-206.

Mayer DJ (1979) Endogenous analgesia systems: neural and behavioral mechanisms. In: Advances in pain research and therapy, Vol 3 (Bonica JJ, Liebeskind JC, Albe-Fessard DG, eds), pp 385-410. New York: Raven.

Mayer DJ, Manning BH (1995) The role of opioid peptides in environmentally-induced analgesia. In: The pharmacology of opioid peptides (Tseng LF, ed), pp 345-395. Chur, Switzerland: Harwood.

Mayer DJ, Price DD (1976) Central nervous system mechanisms of analgesia. Pain 2:379-404.

Mayer DJ, Wolfle TL, Akil H, Carder B, Liebeskind JC (1971) Analgesia from electrical stimulation in the brainstem of the rat. Science 174:1351-1354

McLean S, Rothman RB, Herkenham M (1986) Autoradiographic localization of $\mu$ - and $\delta$-opiate receptors in the forebrain of the rat. Brain Res 378:49-60.

Oliveira MA, Prado WA (1994) Antinociception and behavioral manifestations induced by intracerebroventricular or intra-amygdaloid administration of cholinergic agonists in the rat. Pain 57:383-391.

Paxinos G, Watson C (1986) The rat brain in stereotaxic coordinates, Vol 2. New York: Academic.

Proudfit HK, Anderson EG (1975) Morphine analgesia: blockade by raphe magnus lesions. Brain Res 98:612-618.

Proudfit HK, Levy RA (1978) Delimitation of neuronal substrates necessary for the analgesic action of baclofen and morphine. Eur J Pharmacol 47:159-166.

Proudfit HK, Ycomans DC (1995) The modulation of nociception by enkephalin-containing neurons in the brainstem. In: The pharmacology of opioid peptides (Tseng LF, ed), pp 197-217. Chur, Switzerland: Harwood.
Rizvi TA, Ennis M, Behbehani MM, Shipley MT (1991) Connections between the central nucleus of the amygdala and the midbrain periaqueductal gray: topography and reciprocity. I Comp Neurol 303 $121-131$.

Rodgers RJ (1977) Elevation of aversive threshold in rats by intraamygdaloid injection of morphine sulphate. Pharmacol Biochem $\mathrm{Be}$ hav 6:385-390.

Rodgers RJ (1978) Influence of intra-amygdaloid opiate injections on shock thresholds, tail-flick latencies and open field behaviour in rats. Brain Res 153:211-216.

Sandkühler J, Maisch B, Zimmermann M (1987) The use of local anaesthetic microinjections to identify central pathways: a quantitative evaluation of the time course and extent of the neuronal block. Exp Brain Res 68:168-178.

Tseng LF, Wang Q (1992) Forebrain sites differentially sensitive to $\beta$-endorphin and morphine for analgesia and release of met-enkephalin in the pentobarbital-anesthesized rat. J Pharmacol Exp Ther 261: 1028-1036.

Watkins LR, Wiertelak EP, Maier SF (1993) The amygdala is necessary for the expression of conditioned but not unconditioned analgesia. Behav Neurosci 107:402-405.

Werka T (1994) Post-stress analgesia in rats with partial amygdala lesions. Acta Neurobiol Exp 54:127-132.

Werka T, Marek P (1990) Post-stress analgesia after lesions to the central nucleus of the amygdala in rats. Acta Neurobiol Exp 50:1322.

Winn P, Clark A, Hastings M, Clark J, Latimer M, Rugg E, Brownlee B (1990) Excitotoxic lesions of the lateral hypothalamus made by $\mathrm{N}$-methyl-D-aspartate in the rat: behavioural, histological and biochemical analyses. Exp Brain Res 82:628-636.

Winn P, Stone TW, Latimer M, Hastings MH, Clark AJM (1991) A comparison of excitotoxic lesions of the basal forebrain by kainate, quinolinate, ibotenate, $N$-methyl-D-aspartate or quisqualate, and the effects on toxicity of 2-amino-5-phosphonovaleric acid and kynurenic acid in the rat. Br J Pharmacol 102:904-908

Wolgin DL (1985) Forelimb placing and hopping reflexes in haloperidol- and morphine- treated cataleptic rats. Behav Neurosci 99:423435.

Yaksh TL (1979) Direct evidence that spinal serotonin and noradrenaline terminals mediate the spinal antinociceptive effects of morphine in the periaqueductal gray. Brain Res 160:180-185.

Yaksh TL, Rudy TA (1977) Studies on the direct spinal action of narcotics in the production of analgesia in the rat. $\mathbf{J}$ Pharmacol Exp Ther 202:411-428.

Yaksh TL, Yeung JC, Rudy TA (1976) Systematic examination in the rat of brain sites sensitive to the direct application of morphine: observation of differential effects within the periaqueductal gray. Brain Res 114:83-103.

Yaksh TL, Plant RL, Rudy TA (1977) Studies on the antagonism by raphe lesions of the antinociceptive action of systemic morphine. Eur J Pharmacol 41:399-408.

Yaksh TL, Al-Rodhan NRF, Jensen TS (1988) Sites of action of opiates in production of analgesia. In: Progress in brain research, Vol 77 (Fields HL, Besson J-M, eds), pp 371-394. New York: Elsevier. 